\title{
The eccentricity effect: Target eccentricity affects performance on conjunction searches
}

\author{
MARISA CARRASCO, DENISE L. EVERT, IRENE CHANG, and SVETLANA M. KATZ \\ Wesleyan University, Middletown, Connecticut
}

\begin{abstract}
The serial pattern found for conjunction visual-search tasks has been attributed to covert attentional shifts, even though the possible contributions of target location have not been considered. To investigate the effect of target location on orientation $\times$ color conjunction searches, the target's duration and its position in the display were manipulated. The display was present either until observers responded (Experiment 1), for $104 \mathrm{msec}$ (Experiment 2), or for $62 \mathrm{msec}$ (Experiment 3). Target eccentricity critically affected performance: A pronounced eccentricity effect was very similar for all three experiments; as eccentricity increased, reaction times and errors increased gradually. Furthermore, the set-size effect became more pronounced as target eccentricity increased, and the extent of the eccentricity effect increased for larger set sizes. In addition, according to stepwise regressions, target eccentricity as well as its interaction with set size were good predictors of performance. We suggest that these findings could be explained by spatial-resolution and lateral-inhibition factors. The serial self-terminating hypothesis for orientation $\times$ color conjunction searches was evaluated and rejected. We compared the eccentricity effect as well as the extent of the orientation asymmetry in these three conjunction experiments with those found in feature experiments (Carrasco \& Katz, 1992). The roles of eye movements, spatial resolution, and covert attention in the eccentricity effect, as well as their implications, are discussed.
\end{abstract}

A good deal of current research assumes that covert shifts of attention play an important role in visual-search tasks. In fact, the absence or presence of these attentional shifts has been said to characterize the nature of the search process: In the preattentive stage, search time is unaffected by the number of items in the display, search is said to be parallel, and no shifts are considered to have occurred; in the attentive stage, search time increases as a function of the number of items in the display, search is said to be serial, and shifts are considered to have taken place (e.g., Treisman, 1982, 1986, 1991; Treisman $\&$ Gelade, 1980; Wolfe, 1994). Surprisingly, visualsearch theories have not taken into account the effect of target location on search efficiency. Theories of visual search have been based on performance averaged across all locations of the display, without taking into consideration the inherent constraints of the retina. Given that spatial resolution is better for the fovea than for the periphery (e.g., DeValois \& DeValois, 1988), and that lateral interference is more pronounced in the periphery

This study was supported by the National Science Foundation (NY1 Grant SBR-9357986), by an AAUW American Fellowship to M.C., and by Ford summer grants to I.C. and S.M.K. Parts of this study were presented at the 32nd meeting of the Psychonomic Society, November 1991, and at the 16th European Conference on Visual Perception, August 1993. We would like to thank reviewers Glyn Humphreys and Jeremy Wolfe for helpful comments on a previous version of this paper, as well as Nicole P. Hubbard, Krista Johansen, Tracy McLean, and Pepper Williams for their assistance in analyzing data. Correspondence regarding this paper should be addressed to M. Carrasco, Department of Psychology, New York University, 6 Washington Place, New York, NY 10003-1055 (e-mail: marisa@xp.psych.nyu.edu). than in the fovea (e.g., Breitmeyer, 1984), processing may be inherently better for conjunction targets located at the fovea than at the periphery. Further, the literature has largely failed to recognize the fact that if detecting the target requires foveal processing, observers would have to shift eye fixation from one stimulus or region of the display to the next, and serial search would necessarily take place. The possible interaction between overt shifts of attention (eye movements) and covert shifts of attention (noneye movements) has not been adequately explored (Kinchla, 1992). Investigating the roles of eye movement and target location in the display is critical for the understanding of both feature and conjunction searches.

Although some researchers have instructed observers to keep their eyes at the fixation point during display presentation (e.g., Enns \& Rensink, 1990a, 1990b), it is very likely that observers make more than one eye fixation during the usual range it takes them to respond (0.5$1.5 \mathrm{sec}$ ), especially with large set sizes (Pashler, 1987a). In fact, eye movements increase for large set sizes for conjunction tasks (Zelinsky, 1994; Zelinsky, Sheinberg, \& Bulthoff, 1993). Given that a serial scan could result from successive eye movements and fixations rather than from sequential focusing of covert attention, it is necessary to clarify the contribution of eye movements to search performance before theorizing about covert attention. Klein and Farrell (1989) and Treisman and Gormican (1988) have concluded that eye movements are not responsible for the normally observed search pattern. However, Zelinsky (1994) has recently conducted a thorough investigation of the oculomotor behavior that ac- 
companies some parallel/serial visual-search tasks, and concluded that a detailed study of eye movements is necessary to illuminate underlying processes of visual search that are not easily addressed using the conventional reaction time (RT) methodology.

\section{Target Location}

Even in the absence of eye movements, there remain retinal differences between the fovea and the periphery in the processing of visual stimuli, as have been documented in various physiological and psychophysical studies of spatial resolution and visual acuity. The central $1.5^{\circ}-2^{\circ}$ of visual angle is the locus of the fovea. There are several interrelated differences between the fovea and the periphery that result in decreased spatial resolution with increasing retinal eccentricity (e.g., DeValois \& DeValois, 1988): There are more receptor cells in the fovea than in the periphery; the size of the receptive fields increases toward the periphery of the eye; fewer photoreceptors converge onto a single ganglion cell at the fovea than at the periphery; and the representation of the fovea is magnified at the lateral geniculate nuclei and the visual cortex. Moreover, according to psychophysical evidence, there is a decrease in contrast sensitivity with increasing retinal eccentricity (Cannon, 1985; Rijsdijk, Kroon, \& van der Wilt, 1980), and whereas low spatial frequency channels are located throughout the retina, high spatial frequency channels congregate in the fovea and decrease toward the periphery (Graham, 1981).

On the basis of this evidence that spatial resolution is better at the center of the retina than at peripheral eccentricities, we believe that target processing should be inherently better at the fovea. Thus, we would expect RT and errors to increase as the target is presented in the more peripheral positions of the display. Moreover, because the size of the receptive fields becomes larger as retinal eccentricity increases, we would also expect lateral masking to affect target detection in a more pronounced way as the target's eccentricity increases (Breitmeyer, 1984). As a stimulus is displaced from fovea to periphery, accuracy decreases and latency increases; this retinal gradient is steeper if the stimulus is surrounded by other items than if it appears alone, and lateral interference is more pronounced in the periphery than in the fovea (e.g., Estes \& Wolford, 1971; Wolford, 1975; Wolford \& Shum, 1980).

Indeed, target location may confound the set-size effect; the extent of the set-size effect may be a function of the target eccentricity in the display. On the one hand, if the items in the display have a constant density, then with greater set sizes, the display would necessarily subtend a larger visual angle. On the other hand, if there is a constant display size, then greater set sizes would necessarily increase display density. As a result, the probability of having neighboring distractors processed by the same or neighboring receptive fields, and consequently the possibility of lateral inhibition and lateral masking, would increase, especially at greater eccentricities. Therefore, the more stimuli that appear at peripheral regions of the display, the more pronounced the set-size effect would be. Indeed, if we were to find that the set-size effect became more pronounced as target eccentricity increases, we would question the sufficiency of covert attentional shifts as the explanation of the serial self-terminating hypothesis for conjunction searches (e.g., Treisman \& Sato, 1990; Wolfe, 1994; see General Discussion).

In the experiments we report in this article, we systematically explored the effects of target location on observers' performance on an orientation $\times$ color conjunction search. We manipulated target location in the display and display duration. In the first experiment, eye movements could take place while observers were searching for the conjunction because the display was present until they responded; as a result, target location did not necessarily correspond to a particular retinal eccentricity. Brief display durations used in Experiments 2 and 3 allowed us to equate field and retinal eccentricities, and thus to address both the effect of preventing eye movements and the role of spatial resolution on search performance. In addition, further shortening display duration in Experiment 3 enabled us to study the effect of reducing the number of covert attentional shifts that could take place while the display was present. Moreover, given that covert attention (e.g., Treisman, 1991; Treisman, Cavanagh, Fischer, Ramachandran, \& von der Heydt, 1990; Treisman \& Sato, 1990) and eye movements (Zelinsky, 1994; Zelinsky et al., 1993) are considered to be more prominent in conjunction searches than in feature searches, comparing the conjunction results of this study with those of features (Carrasco \& Katz, 1992) will allow us to examine whether target location and display duration had a similar effect on searches that are presumably carried out by different underlying processes (parallel vs. serial).

Carrasco and Katz (1992) investigated the role of target location in an orientation feature search when the display was present either until the observer responded (free-viewing condition), for $104 \mathrm{msec}$ (fixed-viewing condition), or for $62 \mathrm{msec}$ (fast-fixed-viewing condition); the first display duration allowed for eye movements, whereas the second and third did not. They found a persistent and pronounced eccentricity effect: Targets located at peripheral locations from the fixation point were more difficult to detect than those located closer to the fixation point, as assessed by both speed and accuracy. As their detailed position analyses illustrate how the hidden variable of target location influences search performance, they show that theories of visual search should not be based on performance averaged across all locations in the display.

On the basis of the premise that observers may move their eyes while serially scanning the display of conjunction searches, one could expect a gradient of detectability characterized by increasing RTs for the target positions that are scanned later. For instance, if observers moved their eyes as in reading text, from left to right and from top to bottom, shorter RTs would be found for the top left portion of the matrix, and longer RTs for the bottom right portion of the matrix. In fact, some studies 
have found that the visual detectability gradient is influenced by the direction in which observers normally read (Efron, Yund, \& Nichols, 1987; Heron, 1957; Mishkin \& Forgays, 1952; Ostrovsky-Solis, Efron, \& Yund, 1991). The fact that the eccentricity effect could not be explained by a conventional eye-movement pattern, and that it was highly similar for the fixed- and free-viewing conditions, indicated that eye movements were not responsible for this effect: Had this been the case, the effect would have been more pronounced for the free- than for the fixedviewing conditions; moreover, since performance should be accurate once the eyes have moved to the target location, we would expect this difference to be more apparent in terms of latency than in terms of accuracy.

Because, in general, performance did not differ significantly for the three viewing conditions, Carrasco and Katz (1992) concluded that brief display duration may be an effective way to study the effects of precluding eye movements on search performance. Although RTs were similar, the error rates increased for both fixed-viewing conditions, indicating that performance was somewhat hampered when the display duration was shortened (the error rates, however, were comparable to many other visual-search studies in which eye movements were not prevented; e.g., Enns \& Rensink, 1990a; Klein \& Farrell, 1989; Treisman \& Gelade, 1980).

\section{Conjunction Asymmetry}

A central finding for the exploration of the role of attention in the feature integration theory (FIT) model has been that of feature asymmetries (Cavanagh, Arguin, \& Treisman, 1990; Treisman, 1985, 1986, 1991, 1993; Treisman et al., 1990; Treisman \& Gormican, 1988). For instance, according to FIT, the existence of an orientation asymmetry--the fact that a tilted target among vertical distractors is detected more efficiently (in a parallel fashion) than a vertical target among tilted distractors (in a serial fashion)-indicates that tilt is encoded by early vision, because it is a deviating value from verticality, the standard feature for the system.

Carrasco and Katz (1992) found an orientation asymmetry in the sense that tilted targets were detected among vertical distractors faster and more accurately than vertical targets were detected among tilted distractors; however, the results did not support the parallel/serial dichotomy that ostensibly underlies the detection of the tilted and vertical targets. The finding that the eccentricity effect was more pronounced for the vertical than for the tilted feature targets could possibly be attributed to covert attentional shifts (Carrasco \& Katz, 1992) that are presumably involved when searching for the vertical but not for the tilted target (Cavanagh et al., 1990; Treisman, 1985, 1986; Treisman et al., 1990; Treisman \& Gormican, 1988). However, the existence of the eccentricity effect for the preattentive tilted target makes it clear that covert attention is not necessary for the eccentricity effect to emerge, and suggests spatial resolution as the underlying factor for the tilted-target eccentricity effect, and a likely explanation for the vertical-target eccentric- ity effect. In an attempt to disentangle the role that covert attention and spatial resolution play in the eccentricity effect, we examined whether there would be a difference in the eccentricity effect found for a conjunction task that is traditionally considered to be performed as a serial process and with covert shifts of attention (e.g., Kinchla, 1992; Treisman, 1993; Treisman \& Sato, 1990; Wolfe, 1992, 1994; Wolfe, Cave, \& Franzel, 1989), in comparison with the eccentricity effect that has already been found for a simple feature task (Carrasco \& Katz, 1992).

Additionally, by utilizing a conjunction task, we were able to determine not only whether the differences between the eccentricity effect for the tilted versus the vertical target found with a feature task would be enhanced with a conjunction task, but also whether a conjunction asymmetry would emerge with a more serial or steeper slope for the vertical versus the tilted target. ${ }^{1}$ On the basis of Treisman's hypothesis and the idea that searchrate trends for known conjunctions can be predicted by assuming additive contributions from each component feature (Treisman \& Sato, 1990), we expected that an asymmetry found at the feature level would also emerge for conjunctions of those features (i.e., that the tilted conjunction target would be detected more efficiently than the vertical conjunction target). Alternatively, we can base our prediction of a conjunction asymmetry on Wolfe's guided search (GS) theory, which proposes that the parallel process guides attention toward likely targets by exciting in the parallel feature maps all of the spatial locations in which the feature components of the known conjunction target are present (Wolfe, 1992, 1994; Wolfe \& Cave, 1990; Wolfe et al., 1989). In this way, there is, at the location containing the target, a double excitation that directs attention to that location in order to accomplish the synthesis of the features. Specifically in the case of the tilted versus the vertical target, Wolfe asserts that the tilted target's high level of salience and left-right activation may more effectively guide the serial search in comparison with the less salient vertical target that contributes no activation.

\section{EXPERIMENTS}

Two issues were explored in the present study: The first concerned the question of whether target position affects search performance. Target position was either $0.7^{\circ}, 1.6^{\circ}, 2.1^{\circ}, 2.6^{\circ}, 2.9^{\circ}$, or $3.5^{\circ}$ of visual angle away from the fixation point. Because observers had time to move their eyes during the display's duration in the free-viewing condition (Experiment 1), retinal eccentricity and field eccentricity did not necessarily correspond in this condition. In contrast, because observers did not have time to move their eyes during the display's duration in both of the fixed-viewing conditions (Experiments 2 and 3 ), retinal eccentricity and field eccentricity did correspond in these conditions. Thus for the former, any eccentricity effect found would be a function of spatial resolution and/or covert attentional shifts and/or eye movements; for the latter, any eccentricity effect found could only have 
been a function of spatial resolution and/or covert attentional shifts. Further, Experiment 3 (fast-fixed-viewing condition) did not only prevent eye movements, it also limited the number of covert attentional shifts that could take place while the display was present. Any similarities/ differences in the eccentricity effect that we might find among the different viewing conditions would help us elucidate the mechanisms underlying visual-search performance.

The second issue explored in this study concerned the question of whether the orientation asymmetry that has been found in feature searches (e.g., Carrasco \& Katz, 1992; Treisman et al., 1990; Treisman \& Gormican, 1988 ) is also present for any or all viewing conditions of a conjunction search. Knowledge of the extent to which conjunction-orientation asymmetries may differ under different viewing conditions will contribute to the understanding of the role of primitive features. We expected shortened display durations to impair detection of the vertical targets more than detection of the tilted targets. Although some researchers (Cohen, 1993; Treisman \& Gormican, 1988) have found that orientation asymmetries are more likely to occur with relatively minimal orientation differences between items (i.e., when the tilted items differed from the vertical items by about $15^{\circ}-18^{\circ}$ ), we decided to employ in the present conjunction experiments the $45^{\circ}$ difference between tilted and vertical elements that we have previously found to produce a feature asymmetry (Carrasco \& Katz, 1992). In the present study, color was chosen as the other dimension for the conjunction target, not only because it has been proposed in Treisman's FIT and Wolfe's GS as being one of the hypothetical feature modules encoded in early vision, but also because it is, like orientation, a dimension that is coded by specific pathways in the visual system (e.g., Livingstone \& Hubel, 1988). The blue and red we used are prototype colors (Treisman \& Gormican, 1988; Wolfe, 1994); thus, they were not expected to be processed in an asymmetrical fashion.

\section{Experiment 1}

In this experiment, the display was present until observers responded. We will refer to this manipulation as the free-viewing condition. Observers searched for a color $X$ orientation conjunction target, which appeared in all possible positions of the display among distractors. Three factors were independently manipulated between trials: target orientation, target presence, and the number of items in the display (set size).

\section{Method}

Observers. Twenty-six students at Wesleyan University participated in an hour-long session, in partial fulfillment of an introductory psychology course requirement. All had normal or correctedto-normal vision and were naive as to the purposes and method of the experiment.

Apparatus and Stimuli. The stimuli were presented on a Macintosh IIx microcomputer with a high-resolution RGB color monitor. Each display consisted of 2, 4, 6, 8, 12, 18, 24, 30, or 36 tilted $\left(-45^{\circ}\right.$ from vertical, $\left.\backslash\right)$ and vertical $(\mid)$ red or blue lines presented against a black background (CIE, International Commission on Color, $x, y$ coordinates: red, $.625, .340$; blue, $.155, .07$ ). The items were scattered among 36 positions on a square grid composed of six rows and six columns. Based on a viewing distance of $57 \mathrm{~cm}$, fixed by a chinrest, the display subtended a $6^{\circ}$ (height) $\times 6^{\circ}$ (width) visual angle. The vertical stimuli in the display subtended about $0.5^{\circ}$ height $\times 0.03^{\circ}$ width of visual angle, and the tilted stimuli about $0.45^{\circ}$ height $\times 0.45^{\circ}$ width. The target and distractor colors were both set at $92 \%$ of maximum luminance. When the target was present, it appeared at $0.7^{\circ}, 1.6^{\circ}, 2.1^{\circ}, 2.6^{\circ}, 2.9^{\circ}$, or $3.5^{\circ}$ of eccentricity from fixation point.

Procedure. Each observer was told that half of the displays would contain a target (either a red tilted line or a red vertical line), and that his or her task was to press the yes key of the computer keyboard when the target was present and the no key when the target was absent, with the index or middle finger of their dominant hand; half of the observers used their index finger and half used their middle finger for a yes response. The display was present until a response was made. The observers were instructed to respond as rapidly and as accurately as possible, since both speed and accuracy were to be recorded. A tone indicated that the response was incorrect. Each trial began with the presentation of a fixation point $\left({ }^{+}\right)$, which appeared at the center of the display for $1,200 \mathrm{msec}$. There were six experimental blocks, each of which consisted of 72 randomized trials ( 9 set sizes $\times 8$ times), for a total of 432 experimental trials per observer. In half of the blocks, the observers searched for a red tilted target among blue tilted and red vertical distractors; in the other half of the blocks, they searched for a red vertical target among blue vertical and red tilted distractors. The order of the blocks alternated between searching for the vertical target and searching for the tilted target. The positions occupied by any given display were chosen randomly. Each observer had a practice block of 72 trials for each target type.

\section{Results and Discussion}

General analysis. Owing to the large number of analyses, only the significant main effects and interactions are reported; all pairwise comparisons are NewmanKeuls. Figure 1 presents the observers' mean correct RT and error rates for absent and present trials as a function of set size for the tilted and vertical targets. The linear fit's intercepts of these functions show that for both targets, the minimum RT was faster for present than for absent trials (tilted: 613 and $709 \mathrm{msec}$; vertical: 634 and $722 \mathrm{msec}$, respectively). A within-subjects three-way analysis of variance (ANOVA; orientation $\times$ set size $\times$ target) was performed on the correct RT and error data. All three main effects were significant: RTs were faster for tilted than for vertical targets $[F(1,25)=62.58, p<$ $.001]$, for smaller than for larger set sizes $[F(8,200)=$ $72.71, p<.001]$, and for present than for absent trials $[F(1,25)=55.74, p<.001]$. The three-way interaction for $\mathrm{RT}[F(8,200)=2.02, p<.05]$ indicated that latency increased as a function of set size more rapidly for absent than for present trials, especially so for the vertical targets.

For errors, main effects were also found for the three factors: There were more errors for vertical than for tilted targets $[F(1,25)=6.22, p<.05]$, for larger than for smaller set sizes $[F(8,200)=7.07, p<.001]$, and for present than for absent trials $[F(1,25)=72.32, p<$ $.001]$. The three-way interaction $[F(8,200)=3.25, p<$ $.01]$ indicated that errors increased more for present than for absent trials, especially so for the vertical targets. 

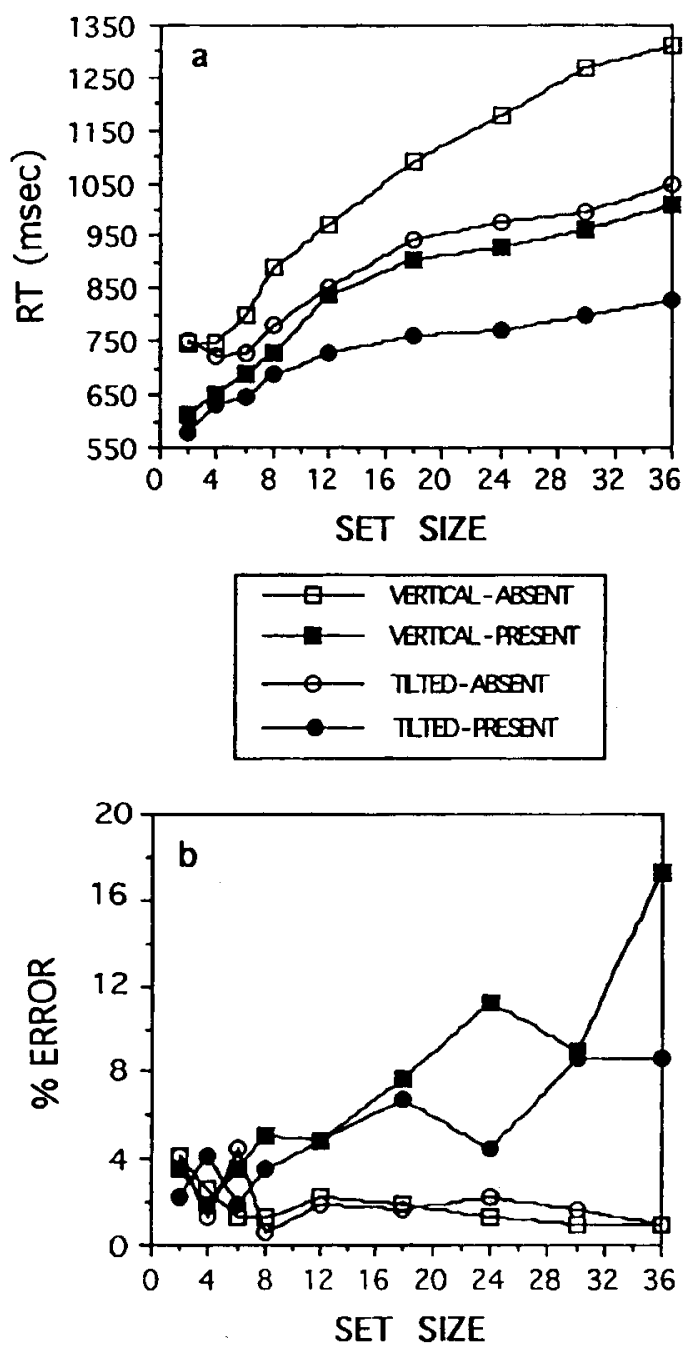

Figure 1. Observers' mean correct reaction times (RTs) and error rates for target-absent and target-present trials as a function of set size for the tilted and vertical targets, under free-viewing conditions (Experiment 1).

RTs and errors increased as set size increased for both absent and present trials. These findings are consistent with findings from other studies (e.g., Duncan \& Humphreys, 1989; Egeth, Virzi, \& Garbart, 1984; Enns \& Rensink, 1990a, 1990b; Pashler, 1987a; Treisman, 1991; Treisman \& Gormican, 1988; Ward \& McClelland, 1989; Wolfe, 1994; Wolfe et al., 1989). A speed accuracy tradeoff was found for target presence: Observers were faster on present than on absent trials, but they made more errors in the former; this tradeoff, however, was not evident for the lower set-size range. These patterns of results, which have often been found for both feature and conjunction searches, will be addressed in the General Discussion.

We found a conjunction-orientation asymmetry in search performance: The tilted conjunction target was detected significantly faster and more accurately than the vertical conjunction target. We had predicted that an asymmetry existing at the feature level would also emerge at the level of conjunctions by assuming additive contributions from each component feature (Treisman \& Sato, 1990), and that the more salient tilted target would have guided the search more efficiently than the vertical target (Wolfe, 1992; Wolfe \& Cave, 1990; Wolfe et al., 1989).

Slope analysis. This experiment shows the importance of testing several set sizes that span a large range, of fitting different functions to the data, and of analyzing individual data. Search rates of less than $10 \mathrm{msec} /$ item are taken to be indicative of parallel processing (e.g., Enns \& Rensink, 1990a, 1990b; Treisman \& Gormican, 1988). According to this criterion, observers searched for the tilted target in a parallel way, and for the vertical target in a serial way. More detailed analyses of the data, however, revealed that this conclusion could not be consistently supported. Table 1 shows the percentage of variance $\left(R^{2}\right)$ accounted for by the linear, logarithmic, and quadratic functions for the tilted and vertical targets. The adjusted $R^{2}$, which takes into consideration the number of predictors and the number of cases, reduces this proportion to a level expected when using this model in a new sample from the same population. For both present and absent targets, the quadratic function had the best fit, followed by the logarithmic function for the present trials, and the linear function for the absent trials.

Further, several regression models were tested. The dependent variable was RT and the main independent variable was set size. Target (absent $=0$, present $=1$ ) and orientation (tilted $=0$, vertical $=1$ ) were assigned as dummy variables. Forward stepwise regression was used to include only variables and interactions that had a significant degree $(p<.05)$ of explanatory value for the model. The quadratic function fit the data best (Table 2 ). The logarithmic and the quadratic fits indicate that the estimate of the msec/item would vary for different ranges of set sizes (i.e., that they were not constant). This argues against the serial self-terminating account of conjunction searches (e.g., Treisman, 1982, 1985, 1986; Treisman \& Gelade, 1980).

The serial self-terminating search is usually assessed by the 2:1 absent/present slope ratio: Whereas the search for the present target is terminated once it is found (on average, after half the items in the display have been examined), the determination of the target's absence requires first that all items be examined. In contrast, for the parallel search, target detection is independent of the number of items in the display, reflected in a $1: 1$ absent/present slope ratio (e.g., Quinlan \& Humphreys, 1987; Treisman, 1991; Treisman \& Gelade, 1980; Treisman \& Gormican, 1988; Treisman \& Sato, 1990; Wolfe et al., 1989; for an argument against the use of 2:1 absent/present slope ratio as indicating serial search processes, see Humphreys \& Müller, 1993). On the basis of each observer's mean RT for each set size, least-square slope estimates for absent and for present trials were obtained (Table 3). Only a few conjunction studies have considered individual slope data (Pashler, 1987a; Treisman, 1991; Wolfe et al., 1989). Two separate analyses 
Table 1

Percentage of Variance $\left(R^{2}\right)$ Accounted for by Linear (Lin), Logarithmic (Log), and Quadratic (Quad) Functions for Target-Absent and Target-Present Trials of Tilted and Vertical Targets for Experiment 1

\begin{tabular}{|c|c|c|c|c|c|c|}
\hline \multirow[b]{3}{*}{ Trial } & \multicolumn{6}{|c|}{ Target Orientation } \\
\hline & \multicolumn{3}{|c|}{ Tilted } & \multicolumn{3}{|c|}{ Vertical } \\
\hline & Lin & $\log$ & $\overline{\text { Quad }}$ & Lin & $\log$ & Quad \\
\hline \multicolumn{7}{|l|}{ Target absent } \\
\hline$R^{2}$ & .938 & .859 & .959 & .971 & .926 & .994 \\
\hline Adjusted $R^{2}$ & .929 & .839 & .935 & .967 & .915 & .990 \\
\hline \multicolumn{7}{|l|}{ Target present } \\
\hline$R^{2}$ & .898 & .986 & .994 & .921 & .965 & .996 \\
\hline Adjusted $R^{2}$ & .884 & .984 & .990 & .910 & .960 & .993 \\
\hline
\end{tabular}

Note-Adjusted $R^{2}=R^{2}-\left(1-R^{2}\right)(p-1) /(n-p)$, where $p$ is the number of predictors and $n$ is the number of cases. All fits were significant at $p<01$.

were performed to evaluate whether the data rejected either the 1:1 parallel hypothesis or the 2:1 serial hypothesis for the conjunction search. ${ }^{2}$ First, by using paired two-tailed $t$ tests (Pashler, 1987a), both the 1:1 and the 2:1 hypotheses were rejected [tilted: $t(25)=2.48, p<$ .05 and $t(25)=-2.18, p<.05$; vertical: $t(25)=3.65$, $p<.001$ and $t(25)=-3.22, p<.01]$. Second, the absent/ present ratio was computed for each observer (Table 3), and a binomial test was used to test the null hypothesis that the proportion of the ratios falling below and above a cutoff point of 1.5 did not significantly differ. If the null hypothesis were rejected, the $1: 1$ or the $2: 1$ hypothesis would be supported when the majority of the ratios fell below or above 1.5 , respectively. However, the binomial tests indicated that the proportion of ratios below and above 1.5 did not significantly differ for either target.

Hence, for this orientation $\times$ color conjunction search, although RTs increased as set size increased, and the slopes were steeper for the absent trials than they were for the present trials, the statistical tests performed on the tilted and vertical targets failed to support either the 2:1 hypothesis for conjunction searches (Treisman \& Gelade, 1980; Treisman \& Sato, 1990) or the alternative $1: 1$ hypothesis that is proposed to be indicative of a parallel process. Although some of the ratios were about $2: 1$, the range of ratios indicates that there was more variability than would be predicted by FIT. Thus, detailed analysis of the search task did not consistently support the serial self-terminating interpretation of the conjunction search in the way that Treisman's coarse examination of slopes and linearity appeared to do (e.g., Treisman, 1982, 1985, 1986, 1988; Treisman \& Gelade, 1980; Treisman \& Sato, 1990). Nonetheless, the fact that the search function was consistently steeper for the vertical than for the tilted target supports the asymmetry results of the General Analysis.

Target-position analysis. To address the effect of target location on search performance in terms of field eccentricity, we obtained the mean correct RTs and errors per target position and eccentricity for each observer, and performed a within-subjects three-way ANOVA (eccentricity from fixation point $\times$ orientation $X$ set size) on the RT and error data. Only the effects not reported previously will be discussed (i.e., the effect of eccentricity and its interaction with other variables).

Figure 2a shows that RT increased as a function of eccentricity $[F(5,125)=29.69, p<.001]$; pairwise comparisons indicated that RTs of targets appearing at $0.7^{\circ}$ were detected faster than those at $1.6^{\circ}-2.1^{\circ}$, which, in turn, were detected faster than those at $2.6^{\circ}-3.5^{\circ}(p<$ .01 ). Errors also increased as a function of eccentricity $[F(5,125)=5.13, p<.001$; see Figure $2 b]$; targets appearing at $0.7^{\circ}-2.1^{\circ}$ induced fewer errors than those at $3.5^{\circ}(p<.01)$. Figures $3 \mathrm{a}$ and $3 \mathrm{~b}$ depict RT and errors for each set size as a function of target eccentricity. The interaction of eccentricity $\times$ set size [RT: $F(40,1000)=$ $2.01, p<.001$; errors: $F(40,1000)=1.56, p<.05]$ indicated that although the set-size effect emerged at all eccentricities $(p<.001)$, it was more pronounced for the larger eccentricities. This is further illustrated in Figures $4 a$ and $4 b$; the set-size effect obtained when the target appeared at $3.5^{\circ}$ was steeper than that for $0.7^{\circ}$ of eccentricity. These figures also show that the eccentricity effect was more pronounced for larger than for smaller set sizes.

Tables $4 \mathrm{~A}$ and $4 \mathrm{~B}$ show the results of stepwise regressions performed on the present trials when eccentricity

Table 2

Stepwise Regressions for Experiment 1

\begin{tabular}{|c|c|c|c|c|c|c|}
\hline & Formula: RT $=$ Intercept $+\sum$ slope(predictors) & $R^{2}$ & Adjusted $R^{2}$ & $F$ & $p$ & $S E$ \\
\hline Linear & $\mathrm{RT}=715.1-92.0(T A R)+10.4(S)-4.9(S * T A R)+7.1(S * O R)$ & .961 & .956 & 190.11 & .000 & 37.8 \\
\hline Logarithmic & $\mathrm{RT}=508.6+150.1(L S)-68.3(L S * T A R)+52.9(L S * O R)$ & .940 & .935 & 168.37 & .000 & 45.9 \\
\hline Quadratic & $\mathrm{RT}=663.3-92.0(T A R)+20.0(S)-0.3(S * S)-4.9(S * T A R)+7.1(S * O R)$ & .983 & .980 & 341.92 & .000 & 25.5 \\
\hline
\end{tabular}

Note--Variables: $T A R=\operatorname{target} ; S=$ set size; $O R=$ orientation; $L S=\log$ of set size.

Formulas: Linear, $\mathrm{RT}=$ intercept + constant $(T A R)+\operatorname{constant}(O R)+\operatorname{constant}(S)+\sum$ constant(interaction);

Logarithmic, $\mathrm{RT}=$ intercept + constant $(T A R)+$ constant $(O R)+\operatorname{constant}(L S)+\sum$ constant(interaction);

Quadratic, $\mathrm{RT}=$ intercept + constant $(T A R)+\operatorname{constant}(O R)+\operatorname{constant}(S)+\operatorname{constant}(S * S)+\sum$ constant(interaction). 
Table 3

Slopes per Observer for Target-Absent (A) and Target-Present (P) Trials for Experiment 1

\begin{tabular}{|c|c|c|c|c|c|c|}
\hline & \multicolumn{6}{|c|}{ Target Orientation } \\
\hline & \multicolumn{3}{|c|}{ Tilted } & \multicolumn{3}{|c|}{ Vertical } \\
\hline & A & $\mathrm{P}$ & $\mathrm{A} / \mathrm{P}$ & A & $\mathrm{P}$ & $\mathrm{A} / \mathrm{P}$ \\
\hline & -2.75 & 2.83 & -0.97 & 2.81 & 7.32 & 0.38 \\
\hline & -2.20 & 3.62 & -0.61 & 11.25 & 16.12 & 0.70 \\
\hline & 0.07 & 2.15 & 0.03 & 7.86 & 9.25 & 0.85 \\
\hline & 0.92 & 6.37 & 0.14 & 11.53 & 13.31 & 0.87 \\
\hline & 3.09 & 7.54 & 0.41 & 19.94 & 22.77 & 0.88 \\
\hline & 1.30 & 2.55 & 0.51 & 4.82 & 5.10 & 0.95 \\
\hline & 3.46 & 5.73 & 0.60 & 7.67 & 7.30 & 1.05 \\
\hline & 3.94 & 4.91 & 0.80 & 6.39 & 6.05 & 1.06 \\
\hline & 4.56 & 5.55 & 0.82 & 16.41 & 14.08 & 1.17 \\
\hline & 7.50 & 8.59 & 0.87 & 12.43 & 9.09 & 1.37 \\
\hline & 10.10 & 9.64 & 1.05 & 19.35 & 13.77 & 1.41 \\
\hline & 11.00 & 9.94 & 1.11 & 11.66 & 8.14 & 1.43 \\
\hline & 4.60 & 3.98 & 1.16 & 33.80 & 22.20 & 1.52 \\
\hline & 10.11 & 7.10 & 1.43 & 20.71 & 13.57 & 1.53 \\
\hline & 6.96 & 4.48 & 1.55 & 8.12 & 5.05 & 1.61 \\
\hline & 18.10 & 11.45 & 1.58 & 19.50 & I 1.80 & 1.65 \\
\hline & 13.74 & 7.72 & 1.78 & 18.90 & 10.73 & 1.76 \\
\hline & 18.88 & 10.09 & 1.87 & 9.03 & 4.95 & 1.82 \\
\hline & 23.94 & 12.26 & 1.95 & 17.24 & 9.42 & 1.83 \\
\hline & 14.60 & 6.50 & 2.24 & 14.93 & 8.10 & 1.84 \\
\hline & 8.95 & 3.74 & 2.40 & 26.22 & 13.99 & 1.87 \\
\hline & 24.42 & 9.05 & 2.70 & 32.94 & 16.95 & 1.94 \\
\hline & 10.71 & 3.66 & 2.93 & 17.52 & 8.28 & 2.12 \\
\hline & 21.11 & 7.07 & 2.98 & 31.02 & 14.29 & 2.17 \\
\hline & 36.14 & 10.11 & 3.58 & 28.46 & 12.58 & 2.26 \\
\hline & 11.54 & 2.88 & 4.01 & 54.87 & 17.84 & 3.08 \\
\hline Mean & 10.18 & 6.52 & 1.42 & 17.90 & 11.62 & 1.50 \\
\hline$S E$ & 1.82 & 0.58 & 0.24 & 2.25 & 0.97 & 0.12 \\
\hline Median & 9.52 & 6.44 & 1.29 & 16.83 & 11.27 & 1.52 \\
\hline Group & 10.18 & 6.52 & 1.56 & 17.90 & 11.62 & 1.54 \\
\hline
\end{tabular}

was and was not taken into consideration. These regressions revealed some interesting findings. (1) In both cases, the linear function had the lowest fit. The logarithmic and the quadratic fits were highly similar. (2) Considering target eccentricity as a predictor markedly improved the adjusted $R^{2}$ as well as the $F$ values of these functions. (3) Although it is generally assumed that there is a linear relationship between set size and RT, set size per se was no longer a significant predictor. However, target eccentricity and its interaction with set size were significant predictors.

These results illustrate that the target's degree of eccentricity from the fixation point was a critical variable in determining search performance. Both RT and errors increased as target eccentricity increased. They also confirm the eccentricity effect described for detection of features (Carrasco \& Katz, 1992). Further, target eccentricity interacted with set size. In general, with increasing eccentricity, the extent of the set-size effect became more pronounced; there was a steeper increase in RT and errors. In addition, the extent of the eccentricity effect increased for larger set sizes. (For implications of these findings, see General Discussion.)

In this experiment, the display was present until observers indicated that they had found a conjunction target; hence, saccadic eye movements may have taken place, especially for the larger set sizes. Nonetheless, the pattern of the eccentricity effect clearly demonstrates that observers were neither searching the displays by moving their eyes from left to right and from top to bottom, as in reading text (e.g., Efron et al., 1987; Heron, 1957; Mishkin \& Forgays, 1952; Ostrovsky-Solis et al., 1991), nor engaging in a random search. In any case, if eye movements took place during the search, field eccentricity and retinal eccentricity did not necessarily correspond; thus, the eccentricity effect found in this experiment could have been due to eye movements, to covert attentional shifts, or to spatial resolution. After documenting the existence of the eccentricity effect for conjunction searches, we wanted to disentangle these possibilities; thus, the following experiment was designed to test whether this eccentricity effect would still be present when eye movements were prevented. The displays appeared on the screen for a brief amount of time $(104 \mathrm{msec})$. Because it is estimated that $200-300 \mathrm{msec}$ are needed for saccades to occur (e.g., Mayfrank, Kimmig, \& Fischer, 1987), it is generally agreed that if the display duration is less than $180 \mathrm{msec}$, saccadic eye movements cannot take place while the display is present (e.g., Klein \& Farrell, 1989; Treisman \& Gormican, 1988).

It has been concluded that several covert attentional shifts may take place during a single eye fixation (e.g., Eriksen \& Webb, 1989; Eriksen \& Yeh, 1985; Murphy \& Eriksen, 1987; Sagi \& Julesz, 1987; Treisman \& Gormican, 1988). Various models (e.g., the spotlight, zoomlens, and gradient models) have been proposed to illustrate the way in which covert attentional shifts may occur (e.g., Kramer \& Jacobson, 1991). These three models would differentially predict the way in which observers' performance would vary as a function of target position, according to their viewpoint on the quality of processing within the attended area. If covert attentional shifts influenced the eccentricity effect, the zoom-lens and gradient models would provide a better account of the eccentricity effect than the spotlight model.

The spotlight model compares attention to a source of light that illuminates the region of the visual field being attended to, analogous to a spotlight illuminating a specific location on a stage (Hurlbert \& Poggio, 1985; LaBerge, 1983; Posner, Snyder, \& Davidson, 1980; Prinzmetal, Presti, \& Posner, 1986; Treisman \& Gormican, 1988; Wolfe et al., 1989; Wolfe, Yu, Stewart, Shorter, \& Cave, 1990). This spotlight can move anywhere in the visual field (Eriksen, 1990), but its resources cannot be divided (e.g., Eriksen \& Yeh, 1985; Posner et al., 1980). Thus, an increase in search-field size results in an increase in search time (for an exception, see Cheal \& Lyon, 1989, in which the time required for attentional shift was independent of distance). For the spotlight to explain the eccentricity effect, one would have to postulate that this beam moved in a rather peculiar way-starting from fixation and gradually moving out to periphery. Further, because the same amount of errors would be expected for each location across the visual field once the beam has illuminated them, this analogy cannot explain the pattern of errors characterizing the eccentricity effect. 
FREE FIXED

FAST-FIXED

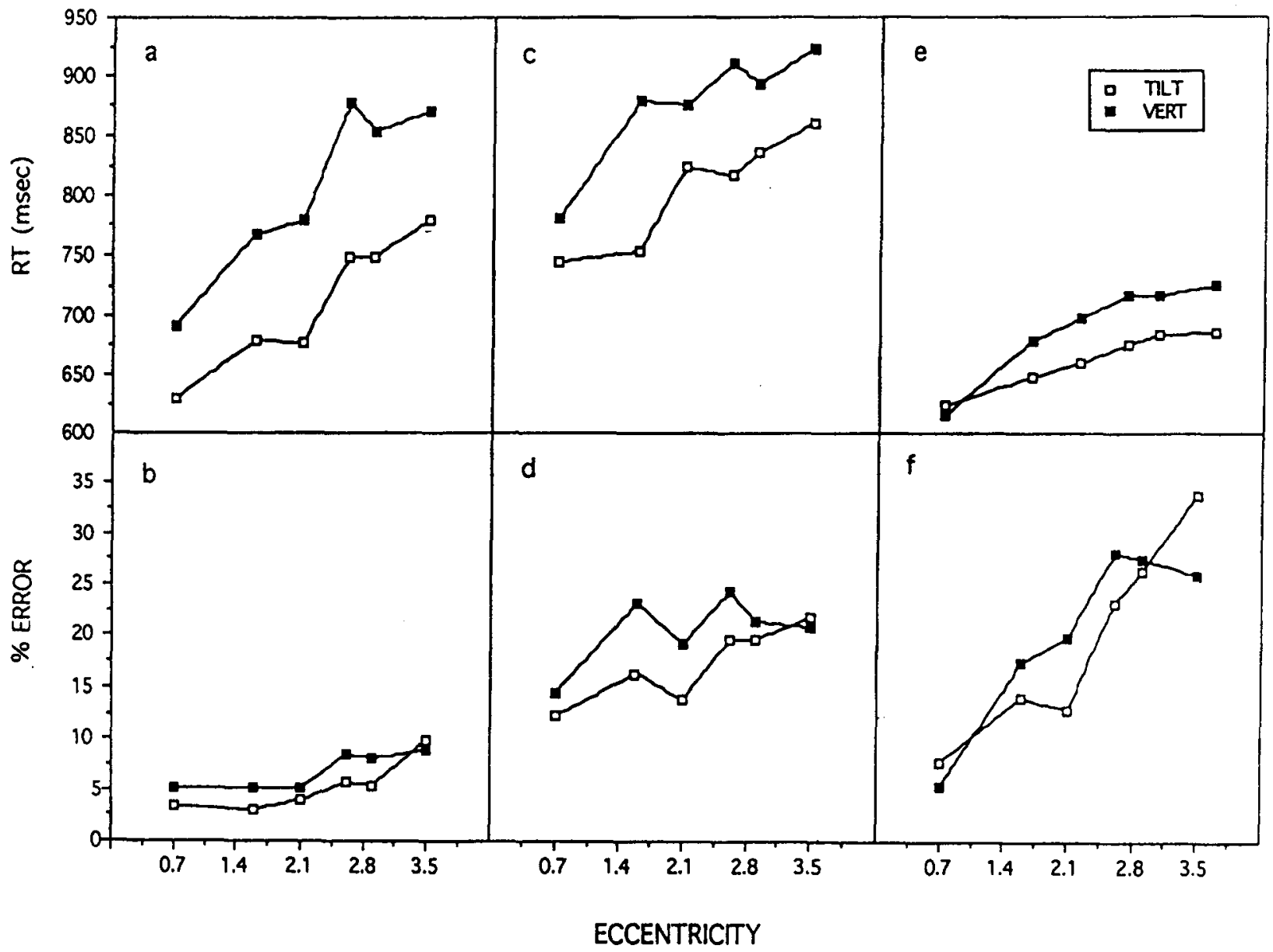

Figure 2. Observers' mean correct reaction times (RTs) and error rates for tilted and vertical targets as a function of target eccentricity, under free-, fixed-, and fast-fixed-viewing conditions (Experiments 1, 2, and 3, respectively).

The zoom-lens model likens the attentional mechanism to a camera lens with a variable aperture. Attention, like a zoom lens, may be expanded to take in the entire display or may be restricted to a single item. This mechanism contains a limited amount of resources, which are allocated according to the situation. The expansion of the scan to include more information within a larger area results in a corresponding loss in spatial resolution; therefore, the stimuli within that field are processed less efficiently. If processing resources were required to make finer discriminations, the lens would zoom in on the appropriate stimuli (Eriksen, 1990; Eriksen \& Murphy, 1987; Eriksen \& St. James, 1986; Shulman, Sheehy, \& Wilson, 1986; Shulman \& Wilson, 1987). Gradient models suggest that processing efficiency varies over the visual field in a continuous fashion; it decreases gradually from the center to the periphery of the attentional field (Andersen, 1990; Andersen \& Kramer, 1993; Downing, 1988; Downing \& Pinker, 1985). The zoom-lens and gradient models are related and are not easily distinguishable (Andersen \& Kramer, 1993). Both of them could account for the eccentricity effect under different as- sumptions. The zoom-lens model could only account for the eccentricity effect if the lens were to focus in the center of the display and gradually expand until the target is found. The gradient model could account for the eccentricity effect if it is assumed that it is centered at the fixation point and that the gradient would be widely focused, given that the target location is not known to observers.

\section{Experiment 2}

This experiment examined the effects of target position and orientation asymmetry when the possibility of saccadic eye movements was eliminated while the display was present. The target appeared in all possible locations and the display was present for only $104 \mathrm{msec}$. Thus, field eccentricity and retinal eccentricity were equated. We will refer to this manipulation as the fixed-viewing condition.

\section{Method}

Observers. A different group of 26 students from the same pool of observers as in Experiment 1 voluntarily participated in the experiment.

Apparatus and Stimuli. These were the same as in Experiment 1. 

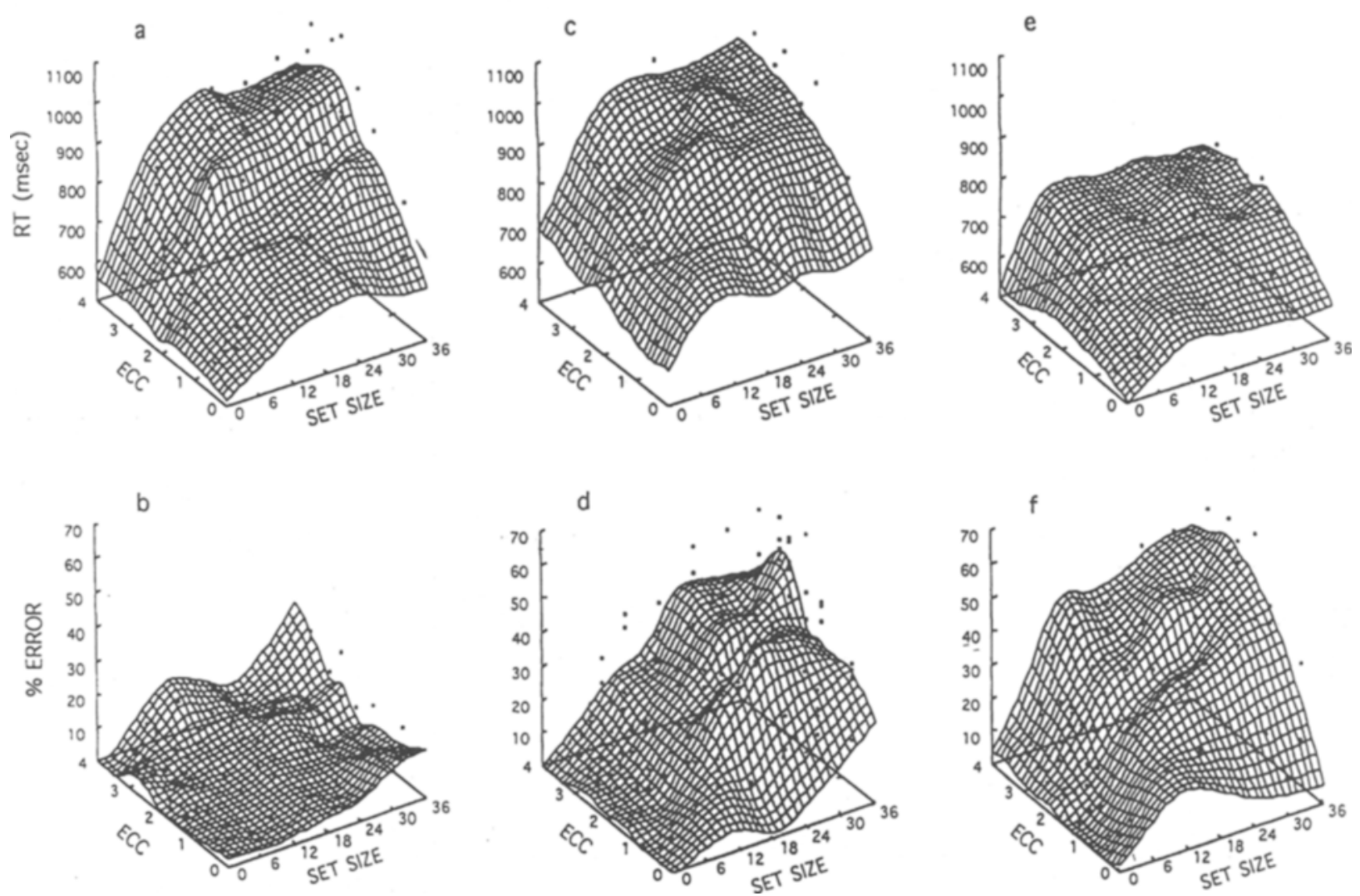

Figure 3. Observers' mean correct reaction times (RTs) and error rates as a function of set size and target eccentricity, under free-, fixed-, and fast-fixed-viewing conditions (Experiments 1, 2, and 3, respectively).

Procedure. The instructions were the same as in Experiment 1 , with the addition that the observers were asked to fixate their eyes in the middle of the screen throughout the trial. They were informed that the displays would only be on the screen for a brief amount of time, that would not be long enough for them to move their eyes. A plus or minus feedback sign in the middle of the screen indicated whether their response was correct $(+)$ or incorrect $(-)$, and served as the fixation point for the next trial. There were six experimental blocks, each of which consisted of 108 randomized trials, for a total of 648 experimental trials per observer. As in Experiment 1, for half of the blocks, the observers searched for the red tilted line, and for the other half, they searched for the red vertical line. There were three experimental blocks for each target type, which only allowed for three different set sizes to be displayed in a particular block of trials. One block for each target type displayed the set sizes of 2,8, and 24, another displayed those of 4.12 , and 30 , and a third displayed those of 6,18 , and $36 .{ }^{3}$ Prior to data collection, each observer had one practice block of 108 trials for each target type.

\section{Results and Discussion}

General analysis. Figure 5 presents the observers' mean correct RTs and error rates for absent and present trials as a function of set size for the tilted and vertical targets. The linear fit's intercepts of these functions show that for both targets, the minimum RT was faster for pre- sent than for absent trials (tilted: 714 and $801 \mathrm{msec}$; vertical: 751 and $844 \mathrm{msec}$, respectively). Main effects for RT were found for all three factors of a within-subjects threeway ANOVA: RTs were faster for tilted than for vertical targets $[F(1,25)=11.36, p<.01]$, for smaller than for larger set sizes $[F(8,200)=61.81, p<.001]$, and for present than for absent trials $[F(1,25)=49.88, p<.001]$.

Main effects were significant for errors for all three factors: There were more errors for vertical than for tilted targets $[F(1,25)=26.00, p<.001]$, for larger than for smaller set sizes $[F(8,200)=183.92, p<.001]$, and for present than for absent trials $[F(1,25)=21.74, p<.001]$. Simple effects indicated that set size $\times$ target $[F(8,200)=$ $11.65, p<.001]$ and orientation $\times$ set size $[F(8,200)=$ $3.14, p<.01]$ interacted because, for set sizes of 12 and above, there were more errors for target presence than for target absence $(p<.05)$, and for the vertical target than for the tilted target $(p<.05)$. For this range of set sizes, a speed-accuracy tradeoff was found for target presence: Observers were faster on target-present than on targetabsent trials, but made more errors in the former.

The orientation asymmetry found for conjunctions in Experiment 1 was replicated. Even under this limited viewing condition, the tilted target was detected signifi- 
FREE

FIXED

FAST-FIXED

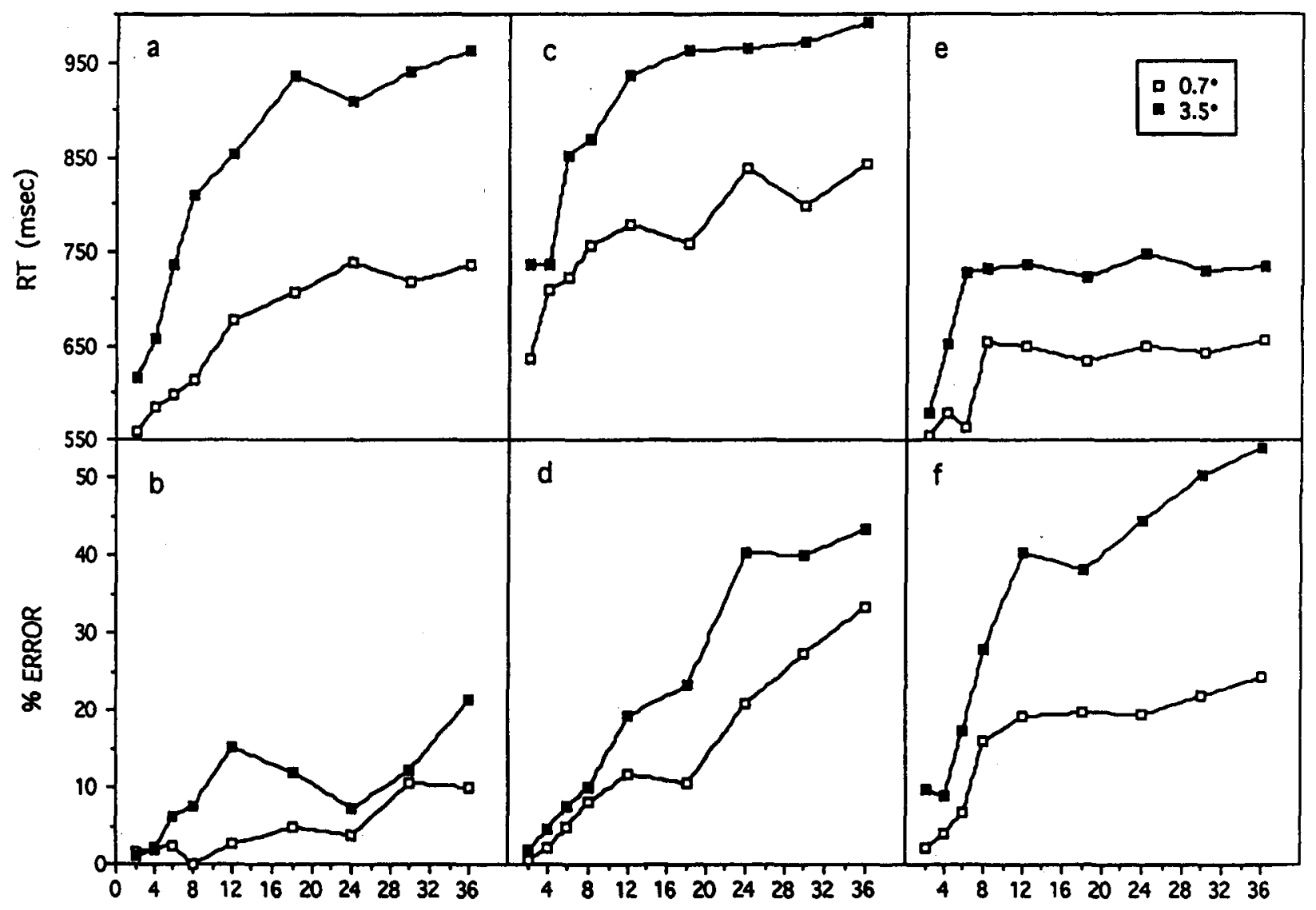

SET SIZE

Figure 4. Observers' mean correct reaction times (RTs) and error rates as a function of set size for targets appearing at $0.7^{\circ}$ and $3.5^{\circ}$ of eccentricity, under free-, fixed-, and fast-fixed-viewing conditions (Experiments 1, 2, and 3, respectively).

cantly faster and more accurately than the vertical target. These results further extend Treisman's hypothesis of asymmetries in feature searches (Cavanagh et al., 1990; Treisman \& Gormican, 1988; Treisman \& Souther, 1985).

Target position. RT increased as a function of eccentricity $[F(5,125)=20.06, p<.001$; see Figure $2 c]$; pairwise comparisons indicated that RTs of targets appearing at $0.7^{\circ}$ were detected faster than those at $1.6^{\circ}$ $(p<.01)$, which were detected faster than those at $2.1^{\circ}$, which, in turn, were detected faster than those at $3.5^{\circ}$ $(p<.05)$. Errors also increased as a function of eccentricity $[F(5,125)=5.27, p<.001$; see Figure $2 \mathrm{~d}]$; targets appearing at $0.7^{\circ}$ had fewer errors than those at all eccentricities $(p<.01)$ except $2.1^{\circ}$. The interactions of eccentricity $\times$ set size [RT: $F(40,1000)=1.84, p<.005$; errors: $F(40,1000)=2.99, p<.001]$ indicated that although the set-size effect emerged at all eccentricities $(p<$ .001 ), it was more pronounced for the larger eccentricities (Figures $3 \mathrm{c}$ and $3 \mathrm{~d}$ ). As in the previous experiment, the set size was more pronounced for targets appearing at $3.5^{\circ}$ than at $0.7^{\circ}$ (Figures $4 \mathrm{c}$ and $4 \mathrm{~d}$ ). As can be seen in these figures, these interactions also revealed that the ec- centricity effect was more pronounced for larger than for smaller set sizes.

The stepwise regressions performed on the present trials when target eccentricity was and was not a predictor (Tables $4 \mathrm{a}$ and $4 \mathrm{~b}$ ) also attest to the relevance of target eccentricity, which markedly improved the adjusted $R^{2}$ as well as the $F$ value of these regressions. As in Experiment 1 , the logarithmic and quadratic functions accounted for more of the data variability than the linear function did. Either target eccentricity (linear and quadratic functions) or its interaction with set size (logarithmic function) were significant predictors of search performance.

The target-position analysis was especially informative in this experiment. Because the viewing time was reduced and eye movements were precluded, retinal eccentricity and field eccentricity corresponded to each other. Given that spatial resolution decreases along retinal eccentricity, and/or that observers may not have time to move (spotlight) or to adjust (zoom lens) their covert attention to all different display positions while the display is present, RTs and errors should be greater at pe- 
Table 4a

Stepwise Regressions for Linear, Logarithmic, and Quadratic Functions for Target-Present Trials When Target Eccentricity Is a Predictor

\begin{tabular}{|c|c|c|c|c|c|c|}
\hline & Formula: $\mathrm{RT}=$ Intercept $+\sum$ slope(predictors) & $R^{2}$ & Adjusted $R^{2}$ & $F$ & $p$ & $S E$ \\
\hline \multicolumn{7}{|c|}{ Experiment 1} \\
\hline Linear & $\mathrm{RT}=572.5+24.5(E)+2.5(S * E)+6.0(S * O R)$ & .860 & .856 & 213.30 & .000 & 52.9 \\
\hline Logarithmic & $\mathrm{RT}=515.4-52.0(O R)+23.5(L S)+26.1(L S * E)+62.1(L S * O R)$ & .916 & .913 & 280.17 & .000 & 41.3 \\
\hline Quadratic & $\mathrm{RT}=552.5+2.0(S)+10.5(E * O R)+6.8(S * E)+4.8(S * O R)-0.1(S * S * E)$ & .919 & .915 & 230.49 & .000 & 40.8 \\
\hline \multicolumn{7}{|c|}{ Experiment 2} \\
\hline Linear & $\mathrm{RT}=634.5+44.9(E)+4.8(S)+4.1(S * O R)$ & .763 & .756 & 111.67 & .000 & 55.1 \\
\hline Logarithmic & $\mathrm{RT}=621.1+36.9(L S)+17.8(L S * E)+31.5(L S * O R)$ & .858 & .854 & 209.97 & .000 & 42.6 \\
\hline Quadratic & $\mathrm{RT}=569.9+44.9(E)+14.9(S)-0.3(S * S)+7.7(S * O R)-0.1(S * S * O R)$ & .858 & .851 & 122.93 & .000 & 43.1 \\
\hline \multicolumn{7}{|c|}{ Experiment 3} \\
\hline Linear & $\mathrm{RT}=617.7+1.3(S * E)+14.3(E * O R)$ & .577 & .569 & 71.75 & .000 & 40.1 \\
\hline Logarithmic & $\mathrm{RT}=497.9+24.9(E)+46.0(L S)+13.0(E * O R)$ & .775 & .768 & 119.39 & .000 & 29.4 \\
\hline Quadratic & $\mathrm{RT}=572.5+2.6(S)+13.6(E * O R)+3.7(S * E)-0.1(S * S * E)$ & .753 & .744 & 78.61 & .000 & 31.0 \\
\hline
\end{tabular}

Note-Variables: $O R=$ orientation; $E=$ eccentricity; $S=$ set size; $L S=\log$ of set size.

Formulas: Linear, $\mathrm{RT}=$ intercept $+\operatorname{constant}(E)+\operatorname{constant}(O R)+\operatorname{constant}(S)+\sum$ constant(interaction);

Logarithmic, $\mathrm{RT}=$ intercept + constant $(E)+$ constant $(O R)+$ constant $(L S)+\sum$ constant (interaction);

Quadratic, RT $=$ intercept + constant $(E)+$ constant $(O R)+\operatorname{constant}(S)+\operatorname{constant}(S * S)+\sum$ constant(interaction).

Table 4b

Stepwise Regressions for Linear, Logarithmic, and Quadratic Functions for Target-Present Trials When Target Eccentricity Is Not a Predictor

\begin{tabular}{|c|c|c|c|c|c|c|}
\hline & Formula: $\mathrm{RT}=\operatorname{lntercept}+\sum$ slope(predictors) & $R^{2}$ & Adjusted $R^{2}$ & $F$ & $p$ & $S E$ \\
\hline \multicolumn{7}{|c|}{ Experiment 1} \\
\hline Linear & $\mathrm{RT}=623.5+5.8(S)+5.8(S * O R)$ & .676 & .670 & 109.76 & .000 & 80.1 \\
\hline Logarithmic & $\mathrm{RT}=489.4+91.2(L S)+43.2(L S * O R)$ & .720 & .715 & 135.19 & .000 & 74.5 \\
\hline Quadratic & $\mathrm{RT}=562.4+17.1(S)-0.3(S * S)+5.8(S * O R)$ & .726 & .718 & 91.95 & .000 & 74.1 \\
\hline \multicolumn{7}{|c|}{ Experiment 2} \\
\hline Linear & $\mathrm{RT}=734.9+4.8(S)+4.1(S S * O R)$ & .628 & .621 & 88.69 & .000 & 68.7 \\
\hline Logarithmic & $\mathrm{RT}=621.1+76.6(L S)+31.5(L S * O \mathrm{R})$ & .720 & .715 & 134.98 & .000 & 59.6 \\
\hline Quadratic & $\mathrm{RT}=670.2+16.7(S)-0.3(S * S)+4.1(S * O R)$ & .715 & .707 & 86.95 & .000 & 60.5 \\
\hline \multicolumn{7}{|c|}{ Experiment 3} \\
\hline Linear & $\mathrm{RT}=615.3+28.4(O R)+3.1(S)$ & .399 & .388 & 34.90 & .000 & 47.8 \\
\hline Logarithmic & $\mathrm{RT}=553.9+28.4(O R)+46.0(L S)$ & .542 & .534 & 62.20 & .000 & 41.8 \\
\hline Quadratic & $\mathrm{RT}=573.5+28.4(O R)+10.8(S)-0.2(S * S)$ & .521 & .507 & 37.64 & .000 & 42.9 \\
\hline
\end{tabular}

Note-Variables: $O R=$ orientation; $S=$ set size; $L S=\log$ of set size.

Formulas: Linear, RT $=$ intercept + constant $(O R)+$ constant $(S)+\sum$ constant (interaction);

Logarithmic, RT $=$ intercept + constant $(O R)+$ constant $(L S)+\sum$ constant(interaction);

Quadratic, RT + intercept + constant $(O R)+\operatorname{constant}(S)+\operatorname{constant}(S * S)+\sum$ constant(interaction).

ripheral positions. As in the previous experiment, for both tilted and vertical targets, according to both RT and errors, (1) as target eccentricity increased, performance decreased; (2) the extent of the set-size effect became more pronounced with increasing target eccentricity, and (3) the eccentricity effect became more pronounced as set size increased.

Although most estimates of regular saccadic eye movements are well above $100 \mathrm{msec}$ (e.g., Mayfrank et al., 1987), some studies estimate that for humans, express saccades may take as little as $100-140 \mathrm{msec}$ (Fischer \& Ramsperger, 1984; Fischer \& Weber, 1993; Mayfrank et al., 1987). In the next experiment, we further shortened the display duration to definitively rule out the possibility of eye movements. Our aim was to explore whether the findings of Experiment 2 would be replicated. Additionally, because, according to some estimates, covert shifts of attention can be as short as $50 \mathrm{msec}$ (Bergen \& Julesz, 1983; Julesz \& Bergen, 1983; Saarinen \& Julesz, 1991; Sagi \& Julesz, 1987), we found it necessary to limit the number of covert attentional shifts that could take place while the display was present. If covert attention were responsible for the eccentricity effect, we would expect this effect to be less pronounced when fewer attentional shifts could occur (e.g., it is less likely that the "spotlight" would move or that the "zoom lens" would adjust while the display is present).

\section{Experiment 3}

In this experiment, we explored the consequences of reducing the number of covert attentional shifts that could take place while the display was present on search performance. In particular, we investigated whether the eccentricity effect and the conjunction-orientation asym- 

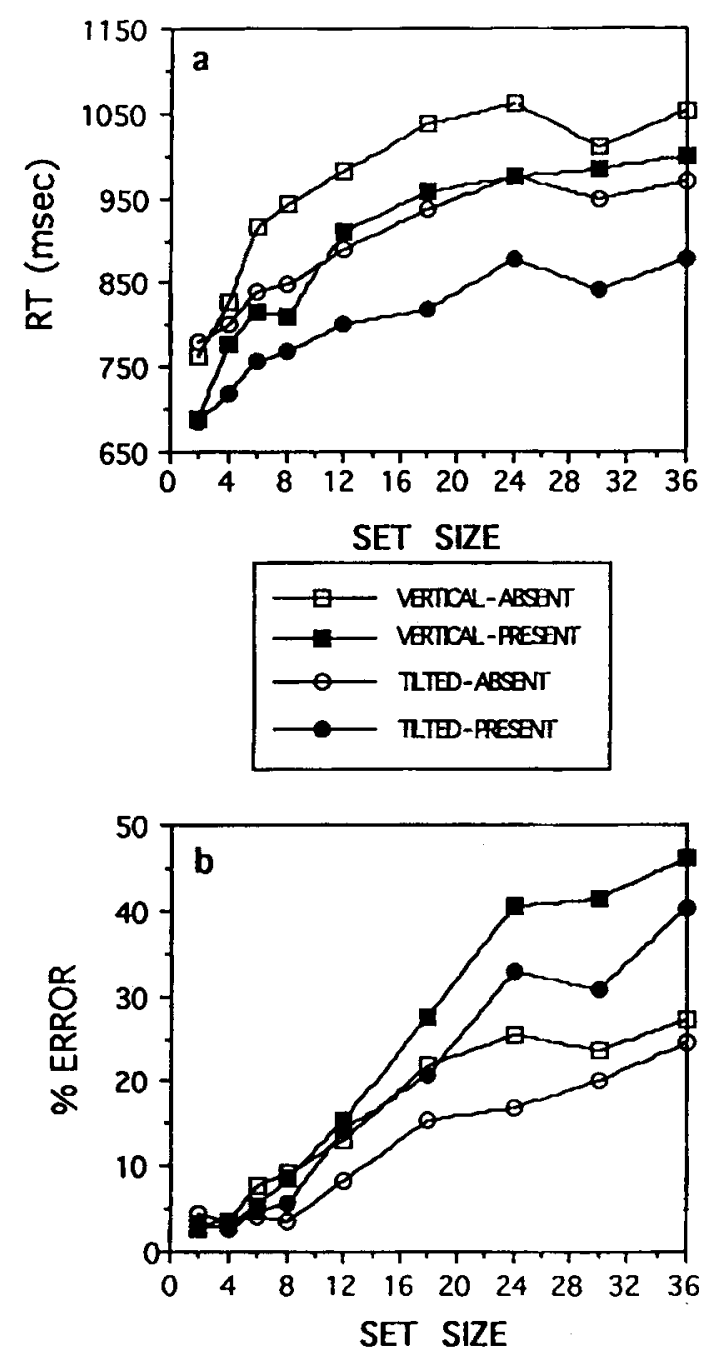

Figure 5. Observers' mean correct reaction times (RTs) and error rates for target-absent and target-present trials as a function of set size for the tilted and vertical targets, under fixed-viewing conditions (Experiment 2).

metry found in the previous experiments would still be present. We shortened the display duration to $62 \mathrm{msec}$. This manipulation will be referred to as the fast-fixedviewing condition.

\section{Method}

Observers. A different group of 26 undergraduate students from the same pool of observers as in the previous experiments voluntarily participated in the experiment.

Apparatus and Stimuli. These were the same as in the previous experiments.

Procedure. The procedure was the same as in Experiment 2, the only difference being that the displays were presented for a shorter duration $(62 \mathrm{msec})$.

\section{Results and Discussion}

General analysis. Figure 6 shows the observers' mean correct RTs and error rates for absent and present trials as a function of set size for the tilted and vertical targets. The linear fit's intercepts of these functions indicate that for both targets, the minimum RT was faster for present than for absent trials (tilted: 605 and $644 \mathrm{msec}$; vertical: 638 and $667 \mathrm{msec}$, respectively). A within-subjects threeway ANOVA was performed on the RT and error data. Main effects were found for all three factors: RTs were faster for tilted than for vertical targets $[F(1,25)=25.33$, $p<.001]$, for smaller than for larger set sizes $[F(8,200)=$ $48.98, p<.001]$, and for present than for absent trials $[F(1,25)=11.57, p<.005]$.

Errors increased more for vertical than for tilted targets $[F(1,25)=3.34, p<.10]$, more for larger than for smaller set sizes $[F(8,200)=137.08, p<.001]$, and more for present than for absent trials $[F(1,25)=18.96, p<$ $.001]$. Simple effects for the set size $\times$ target interaction $[F(8,200)=10.30, p<.001]$ showed that the errors for target presence were greater than those for target absence for set sizes of 8 and above $(p<.05)$.

In this experiment, the tilted target was detected significantly faster and more accurately than the vertical target, even with this very short display duration $(62 \mathrm{msec})$. This result is similar to those found in the previous experiments. As in the previous studies, both RTs and errors increased as a function of set size, and a targetpresence speed-accuracy tradeoff emerged for set sizes of 12 and above: Observers were faster on target-present than on target-absent trials, but they made more errors in the former.

Target position. In this experiment, as in the previous one, the elimination of eye movements allowed us to equate field eccentricity and retinal eccentricity. RT increased as a function of eccentricity $[F(5,125)=16.11$, $p<.001$; see Figure 2e]; pairwise comparisons indicated that RTs of targets appearing at $0.7^{\circ}$ were detected faster than those at $1.6^{\circ}$, which, in turn, were detected faster than those at $2.6^{\circ}-3.5^{\circ}(p<.01)$. Errors also increased as a function of eccentricity $[F(5,125)=15.89, p<.001$; see Figure 2f]; targets appearing at $0.7^{\circ}$ were detected more accurately than those at $1.6^{\circ}-2.1^{\circ}$, which, in turn, were more accurately detected than those at $2.6^{\circ}-3.5^{\circ}$ $(p<.01)$. The interactions of eccentricity $\times$ set size [RT: $F(40,1000)=1.89, p<.001$; errors: $F(40,1000)=$ $2.47, p<.001]$ indicated that although the set-size effect emerged at all eccentricities ( $p<.001)$, it was more pronounced for the larger eccentricities (see Figures $3 \mathrm{e}$ and $3 \mathrm{f}$ ). As in the previous experiments, the set-size effect was more pronounced for $3.5^{\circ}$ than for $0.7^{\circ}$ (see Figures $4 \mathrm{e}$ and $4 \mathrm{f}$ ). These figures also show that the extent of the eccentricity effect became more pronounced as set size increased.

Also, as in the previous experiments, the stepwise regressions performed on the present trials, both taking and without taking eccentricity into account (Tables 4a and $4 \mathrm{~b}$ ), illustrate. that considering target eccentricity as a predictor greatly improved the adjusted $R^{2}$ and the $F$ value of these regressions. The logarithmic regressions had the best fit, closely followed by the quadratic ones; again, the linear regressions had the worst fits. In this experiment, target eccentricity (logarithmic function), as well as its interaction with set size (quadratic function) 

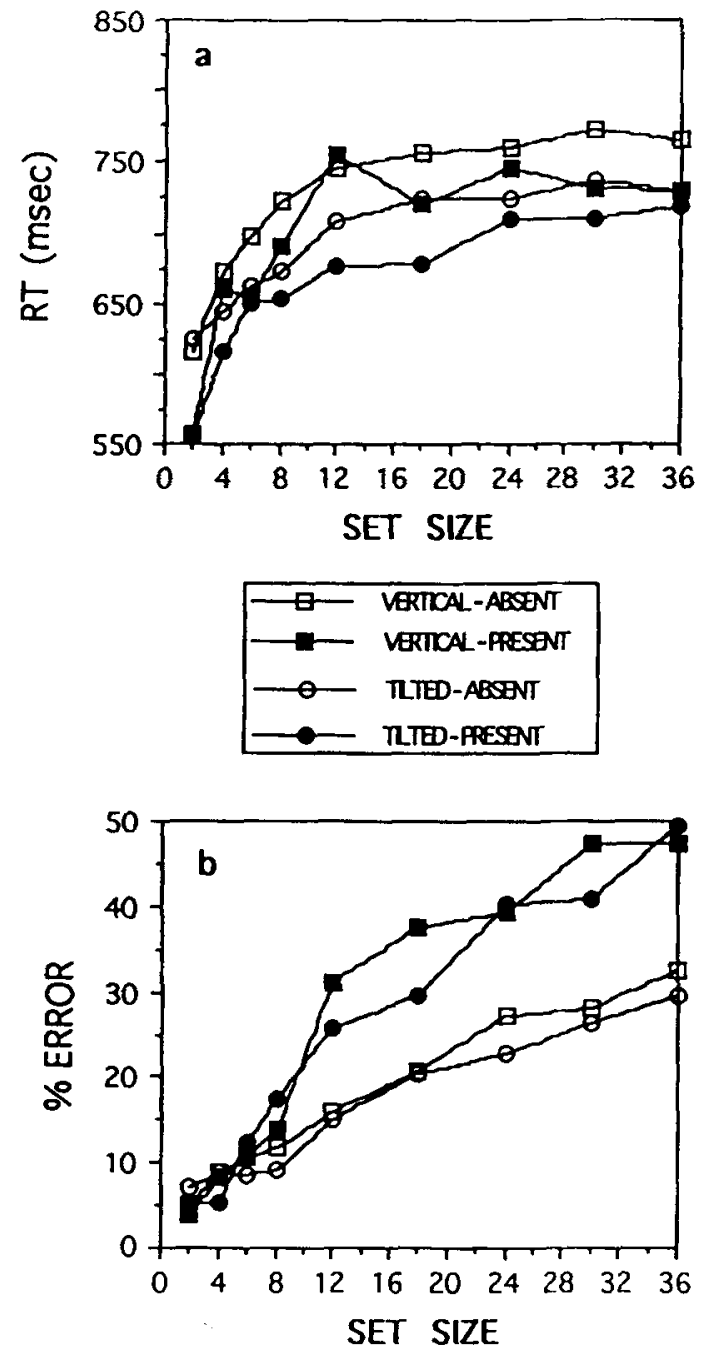

Figure 6. Observers' mean correct reaction times (RTs) and error rates for target-absent and target-present trials as a function of set size for the tilted and vertical targets, under fast-fixed-viewing conditions (Experiment 3).

and with orientation (all three functions), were significant predictors of search performance.

The very short display duration of this experiment did not only eliminate the possibility of eye movements, it also limited the amount of covert attentional shifts that may have taken place while the display was present. As in the previous experiments, the target's position from the fixation point was a critical variable in determining search performance. For all set sizes of both tilted and vertical targets, RTs and errors increased with increasing eccentricity from the fixation point. Moreover, as in the previous experiments, the set-size effect became more pronounced as the target appeared at farther eccentricities, and the eccentricity effect was greater for larger than for smaller set sizes. Because of the short display duration of this experiment, the effect of eccentricity was more pronounced for errors than for RTs. Given that in this experiment, the eccentricity effect could not have been due to eye movements and was not likely to have been a consequence of covert attentional shifts, we suggest that it could be attributed to spatial resolution (see General Discussion).

\section{GENERAL DISCUSSION}

\section{Eccentricity Effect}

Some studies have pointed out that to study attention and perceptual organization, it is necessary to perform a structural analysis of the display (e.g., Kramer \& Jacobson, 1991). For instance, it has been found that the spatial layout of target and distractors is an important factor in directing search (Poisson \& Wilkinson, 1992). A critical issue of the present study was to systematically explore the effect of target position on conjunction-search performance. The findings were clear: The greater the target eccentricity, the slower and less accurate the observers' performance. The eccentricity effect found here is especially noteworthy given that the maximum target eccentricity was only $3.5^{\circ}$ away from fixation point. We would expect the extent of this effect to become more pronounced with greater eccentricities. Both the ANOVA analyses and the stepwise regressions attest to the fact that even within this limited display size, target eccentricity, as well as its interaction with set size, turned out to play a major role in observers' performance. Indeed, when these predictors were taken into consideration, the stepwise regression models were greatly improved (Tables $4 \mathrm{a}$ and $4 \mathrm{~b}$ ). The eccentricity effect has significant implications for current models of visual search, since none of these models takes target position into account.

The extent of the eccentricity effect interacted with display duration. In terms of latency, it was more pronounced for the free- than for the fixed-viewing conditions. In terms of accuracy, the opposite was true: The eccentricity effect was more pronounced for the fast-fixedthan for the fixed-viewing condition, which, in turn, showed a marginally more pronounced eccentricity effect than did the free-viewing condition. These interactions reflect the corresponding ranges that emerged from the RT and error data under the three viewing conditions (see Display Duration, below). Together, the latency and accuracy data indicate that the pattern of the eccentricity effects for the three viewing conditions were highly similar. This proposition is also evidenced by the presence of significant correlations among the three experiments for both RTs and errors per position. Further, significant correlations between the RTs and errors per position for each of the three viewing conditions were found. ${ }^{4}$

The eccentricity effect was present for all set sizes under the three viewing conditions (Figure 2). Note that two revealing interactions emerged in each of the viewing conditions. First, the eccentricity effect became more pronounced as set size increased (Figure 3); that is, the target location was more critical as the display density increased. This finding could be explained by a greater impairing effect of lateral inhibition at higher eccentric- 
ities. Second, even though for a given set size display density was comparable for different target eccentricities (the number of items in the display was the same: 2-36), the set-size effect became more pronounced as target eccentricity increased (Figure 4). This finding could be explained by the spatial resolution of the retinal eccentricity responsible for target detection. In the present study, the extent of the RT interaction between target eccentricity and set size was greater for the free- than for the fixed-viewing conditions, for which, in turn, it was greater than it was for the fast-fixed-viewing conditions. The opposite was true for errors: The interaction was more pronounced for the fixed- than for the free-viewing conditions. Again, together, the latency and accuracy data illustrate the similarity of these interactions under the three viewing conditions.

The fact that the set-size effect became more pronounced as eccentricity increased in all viewing conditions suggests that target eccentricity confounds the setsize effect. Given that at least some of the distractors have to be examined before the conjunctive target can be found, the difficulty of the conjunction search would increase with larger set sizes, since increasing set size would necessarily increase the likelihood of items appearing at peripheral locations. The greater the distance between the most central and the most peripheral target eccentricities, the more misleading it would be to assess performance by averaging across all locations of the display.

As mentioned in the introduction, we conducted this study to try to disentangle the roles of spatial resolution and covert attention as possible factors underlying the eccentricity effect. We created some conditions in which covert attention could potentially play a greater role in the search-namely, (1) conjunctions versus features (Carrasco \& Katz, 1992); (2) display durations that allowed for more covert attentional shifts to take place while the display was present (i.e., free- vs. fixed- vs. fast-fixed-viewing conditions); and (3) orientations that presumably would require more serial processing (i.e., vertical orientations) or less serial processing (i.e., tilted orientations).

Conjunctions versus features. The eccentricity effect obtained here for conjunction searches was similar to that obtained for feature searches (Carrasco \& Katz, 1992). This is supported by the significant correlations of performance at each position between the two tasks for all viewing conditions. ${ }^{5}$ However, in general, the extent of this eccentricity effect was more pronounced for the conjunction search than for the feature search, especially at larger set sizes. The more pronounced eccentricity effect obtained for conjunction searches than for feature searches could be explained by the differential attentional demands posed on conjunction searches than on feature searches. However, according to the conventional criteria used to classify a search as being parallel or serial (e.g., Duncan \& Humphreys, 1989; Egeth et al., 1984; Enns \& Rensink, 1990a, 1990b; Treisman \& Gormican, 1988), only the search for the vertical target in the free-viewing condition would be considered to be serial.
Alternatively, the more pronounced eccentricity effect found for conjunction searches than for feature searches could result from the more complex conjunction stimuli's taxing the visual system to a greater extent than the less complex feature stimuli. Because conjunction stimuli took different values (i.e., tilted or vertical line, and red or blue) in two dimensions (orientation and color), they were more heterogeneous than the feature stimuli, which only varied in one dimension (i.e., tilted or vertical line). In addition, for a given search, all the feature distractors were identical (red tilted or red vertical), whereas there were two types of conjunction distractors (red tilted and blue vertical or blue tilted and red vertical). Given that the visual area that can be processed in a parallel fashion is a function of the similarity between a target and the distractors (e.g., Bergen \& Julesz, 1983) and the homogeneity of the distractors (e.g., Duncan \& Humphreys, 1989, 1992), we would expect that the conjunction distractors would impair search performance more than the feature distractors.

Some researchers have shown that stimuli located in the right visual field are detected more accurately than those in the left visual field. Although a visual-field difference was not found in Carrasco and Katz's (1992) feature-search study, we investigated whether it would be present for conjunction searches, given that it has been suggested (Efron et al., 1987; Efron, Yund, \& Nichols, 1990a, 1990b, 1990c; Yund, Efron, \& Nichols, 1990a, $1990 \mathrm{~b}, 1990 \mathrm{c})$ that a serial scanning mechanism examines the stimuli in the right visual field, followed by the left visual field. For the three experiments reported here, however, ANOVAs of the target position at different eccentricities indicate neither any significant effect of visual field (left vs. right or upper vs. lower; see Table 5$)^{6}$ nor its interaction with target type. (The only exception was that for errors in Experiment 3, there was a more pronounced orientation asymmetry in the left than in the right visual field.) Similarly, there was no evidence of left-right visual field differences in a same-different visual matching task (Lefton \& Haber, 1974), in an object recognition task, or in a priming task (Biederman \& Cooper, 1991).

Free- versus fixed- versus fast-fixed-viewing conditions. The correspondence among the eccentricity effects in the three display durations suggests that observers followed a common search pattern. We concluded that eye movements were not responsible for the eccentricity effect, not only because the distribution of RT and errors does not conform to any conventional eye-movement pattern, but also because eye movements could not take place while the display was present in the fixed-and fast-fixed-viewing conditions.

Despite the fact that we reduced the possible number of covert attentional shifts in the fast-fixed-viewing condition, as compared with the fixed-viewing condition, we found no difference in the eccentricity effect between the two. Covert attention does not appear to be responsible for the eccentricity effect. Even if an iconic representation outlasts the display duration, covert attentional 
Table 5

Mean Reaction Time (RT) and Percentage of Error (\% Err) for Left Versus Right and for Upper Versus Lower Visual Fields

\begin{tabular}{|c|c|c|c|c|c|c|c|c|c|c|c|c|}
\hline \multirow[b]{3}{*}{ Visual Field } & \multicolumn{12}{|c|}{ Experiment } \\
\hline & \multicolumn{4}{|c|}{1} & \multicolumn{4}{|c|}{2} & \multicolumn{4}{|c|}{3} \\
\hline & RT & $S D$ & $\%$ Err & $S D$ & RT & $S D$ & $\%$ Err & $S D$ & $\mathrm{RT}$ & $S D$ & $\%$ Err & $S D$ \\
\hline Left & 744 & 16.5 & 5.1 & 0.6 & 810 & 8.1 & 20.0 & 1.3 & 663 & 10.0 & 23.8 & 1.3 \\
\hline Right & 745 & 13.0 & 6.2 & 0.9 & 836 & 16.3 & 18.4 & 1.6 & 662 & 10.6 & 23.7 & 2.0 \\
\hline Upper & 745 & 15.1 & 6.4 & 1.0 & 815 & 13.2 & 19.2 & 1.6 & 658 & 8.6 & 24.7 & 1.9 \\
\hline Lower & 744 & 14.7 & 4.9 & 0.4 & 830 & 13.1 & 19.2 & 1.3 & 667 & 11.7 & 22.9 & 1.3 \\
\hline
\end{tabular}

shifts would be more limited by the degrading quality of a decaying icon than by a continuously visible display. To address the possibility that the eccentricity effect may result from a readout of the iconic representation, ${ }^{7}$ we report two low-contrast experiments. In these experiments. that were otherwise identical to the present experiments under free- and fixed-viewing conditions, we lowered the contrast between stimuli and background to affect the quality of the iconic representation. If covert attentional shifts were responsible for the eccentricity effect, its extent should increase when the quality of the iconic representation was degraded. In the first experiment, 26 observers searched for a conjunction target when the blue and red target and distractors were set at $50 \%$ of maximum luminance against a black background (Carrasco, Katz, \& Chang, 1993). In the second experiment, 32 observers searched for a conjunction target when the blue and red targets and distractors, as well as the gray background, were all set at $92 \%$ of maximum luminance (Savel, 1991). The slopes for these searches were steeper than those of the experiments reported here. This finding has been reported previously: Low-contrast searches take longer than high-contrast searches (Cohen, 1993; Wolfe et al., 1989). In both experiments, a pronounced eccentricity effect emerged; the search was more efficient when the target appeared near the center of the display, and became less efficient when the target appeared near the periphery of the display. However, the eccentricity functions were highly similar both in shape and size to the ones reported in this article. ${ }^{8}$ These results suggest that, at least for the conditions we tested, the quality of the iconic representation did not affect the extent of the eccentricity effect.

Tilted versus vertical target. In general, the eccentricity effect in conjunction searches was present to a similar extent for both targets. This is in contrast to the pattern found in feature searches, in which the eccentricity effect was more pronounced for the vertical than for the tilted targets (Carrasco \& Katz, 1992). Even though the tilted line may have an advantage over the vertical line and guide the search for orientation $\times$ color conjunctions more effectively, it does not pop out of the display as in a feature search; its advantage is not as large for conjunction searches as it was for feature searches.

Some researchers have controlled for eccentricity from the fixation point by presenting display items on the perimeter of an imaginary circle (e.g., Donnelly,
Humphreys, \& Riddoch, 1991; Duncan \& Humphreys, 1989; Humphreys, Quinlan, \& Riddoch, 1989; Klein \& Farrell, 1989; Pashler, 1987a). However, using circular displays does not necessarily rule out effects of target eccentricity. First, the serial set-size effect may be more pronounced with larger than with smaller circles; even though the eccentricity at which the items appear would be constant within a circle, the farther away the circle is from fixation, the more pronounced the set-size effect would be. Humphreys et al. (1989) did indeed find a less pronounced set-size effect for conjunction targets at $2.2^{\circ}$ than at $4.7^{\circ}$ of eccentricity. Second, for any given eccentricity, after a certain point up to which having neighbors may aid performance, a set-size effect could emerge due to lateral inhibition or lateral masking. As a matter of fact, the influence of target eccentricity on the set-size effect may be hard to circumvent.

Consider the following scenarios that would result as we add items to the display: (1) To keep display density constant around the fixation point, the display size would have to be enlarged, which, in turn, would increase target eccentricity. Whereas for small set sizes, the target would only appear at near eccentricities, for large set sizes, the target would appear at near and at far eccentricities. (2) To keep display size constant, the display would have a larger density, which would result in lateral inhibition, especially at larger eccentricities. (3) If the display size and density of items are kept constant, set size could only be manipulated if the different number of locations that are occupied by different set sizes move randomly within the largest display area. However, even though density would be controlled for, the probability of the target appearing at different locations would vary. For instance, Treisman (1991) had a $5 \times 5$ display, in which the probability of the target appearing at the perimeter of the display was .39 for a set size of 9 , whereas it was .64 for a set size of 25 . At any rate, increasing set size brings about the risk of recruiting more peripheral regions that will slow down performance and inflate the set-size effect, due to decreased acuity and/or increased lateral inhibition. There is no display that assures that target position can be overlooked.

In short, these results support neither eye movements nor covert attentional shifts as an explanation of the eccentricity effect. We suggest that for all feature and conjunction searches we have tested so far, the eccentricity effect may be due to a common underlying factor- 
namely, a physiological constraint of the eye; at greater retinal eccentricities, spatial resolution decreases (e.g., DeValois \& DeValois, 1988) and lateral masking increases (e.g., Breitmeyer, 1984), making target processing inherently better at the fovea than at peripheral eccentricities. This interpretation of the eccentricity effect is in line with the existence of a retinal gradient-accuracy decreases and latency increases as a stimulus is displaced from the fovea to the periphery. The more pronounced effect of target eccentricity for larger than for smaller set sizes agrees with the fact that this retinal gradient becomes steeper when the stimulus is surrounded by other items than it is when it appears alone (Estes \& Wolford, 1971; Wolford, 1975; Wolford \& Shum, 1980).

\section{General Performance}

Overall, RT was faster when the target was present than when it was absent, but there were more errors made with the target-present trials. This indicates that a speed-accuracy tradeoff occurred for all the viewing conditions. Although this pattern of results has often been obtained for both feature and conjunction searches, some authors have analyzed the error rates (Enns \& Rensink, 1990a, 1990b; Humphreys et al., 1989; Klein \& Farrell, 1989; Moraglia, 1989a; Pashler, 1987b; Wolfe et al., 1989), but others have not (e.g., Cavanagh et al., 1990; Egeth et al., 1984; Jonides \& Yantis, 1988; Moraglia, 1989b; Pashler, 1987a; Treisman, 1982, 1991). Our finding that the target-absent/target-present speedaccuracy tradeoff was not found for the lower set sizes may be one reason why this tradeoff did not emerge in studies that only tested the lower set-size range (e.g., Chmiel, 1989; Egeth \& Dagenbach, 1991). Moreover, when authors have collapsed their analyses across targetabsent and target-present trials (e.g., Treisman \& Gormican, 1988; Treisman \& Sato, 1990; Wolfe et al., 1990), any differences between these two trial types may have been obscured. In the present experiments, errors increased as RT increased, especially for the present trials, indicating that observers were not simply trading speed for accuracy. This is a common finding, which, in fact, is considered the opposite of a speed-accuracy tradeoff (Wolfe, 1994), and it has not precluded researchers' analysis of slopes (e.g., Duncan \& Humphreys, 1989; Enns \& Rensink, 1990a, 1990b; Treisman, 1991; Wolfe, 1994).

Although it has been stated that parallel and serial are not clear-cut concepts to describe the nature of search performance (e.g., Humphreys \& Müller, 1993; Townsend, 1972, 1990; Wolfe, 1994), very few researchers have investigated this issue systematically (e.g., Cheal \& Lyon, 1992). In the present study, we further evaluated the serial-search hypothesis for conjunctions (Experiment 1). A detailed analysis of the individual and group slopes indicated that neither the fit of the different mathematical functions nor the statistical analysis lent support to the hypothesis that the orientation $\times$ color conjunction target was searched in a serial self-terminating way (e.g., Treisman, 1985, 1986; Treisman et al., 1990; Treisman \& Sato, 1990).
As can be seen in Table 1, the quadratic function had the best fit to the data according to both the simple and the stepwise regressions. However, the logarithmic fit was also very good. Exploring a large number and range of set sizes allowed for nonlinearities to emerge; had fewer set sizes been tested, linear functions may have appeared to be good candidates. For instance, had we tested only three set sizes, and of a smaller range (e.g., 4, 9, and 16; Treisman \& Sato, 1990), we may have concluded that the search was linear and self-terminating. Indeed, as was the case for features (Carrasco \& Katz, 1992), RTs were a nonmonotonic function of set size; they increased for the small set sizes and then approached an asymptote at larger set sizes (Figure 1a).

These search patterns resemble those of some feature searches (Bacon \& Egeth, 1991) and conjunction searches (Wolfe et al., 1989), in that the slopes were steeper for the smaller set sizes and shallower for the larger set sizes. These findings could have resulted from distractor grouping and display density: The larger the set size, the more crowded the display and the more opportunity there would be for distractor grouping. Distractors tend to group as a function of their similarity and proximity (Duncan \& Humphreys, 1989, 1992), and in some instances, adding distractors strengthens perceived grouping (Banks \& Prinzmetal, 1976), which, in turn, would improve observers' performance in both feature and conjunction searches (Bundesen \& Pedersen, 1983; Duncan \& Humphreys, 1989, 1992; Farmer \& Taylor, 1980; Humphreys et al., 1989; Poisson \& Wilkinson, 1992).

This study, and other studies that have failed to find serial functions for conjunction searches (Chmiel, 1989; Egeth et al., 1984; Humphreys \& Müller, 1993; McLeod, Driver, \& Crisp, 1988; Nakayama \& Silverman, 1986; Pashler, 1987a; Steinman, 1987; Ward \& McClelland, 1989; Wolfe \& Cave, 1990; Wolfe et al., 1989), argue against a serial self-terminating model for conjunction search, and suggest that search need not require a random serial examination of each stimulus in the display. A revised version of FIT has proposed that the attentive mechanism operates along a continuum. For example, certain conjunction searches may be better described by a relatively parallel function when targets are highly discriminable relative to a homogeneous background (Treisman, 1990, 1991, 1993; Treisman \& Gormican, 1988; Treisman \& Sato, 1990). However, covert attentional involvement in conjunction searches continues to be inferred from dichotomous indexes-either the 2:1 absent/ present ratio (e.g., Treisman, 1991; Treisman \& Gormican, 1988; Treisman \& Sato, 1990) or the 10-msec cutoff point (e.g., Enns \& Rensink, 1990a, 1990b; Treisman \& Gormican, 1988).

\section{Effects of Display Duration}

To investigate the effects of display duration on conjunction-search performance, we compared the results of the free-, fixed-, and fast-fixed-viewing conditions; only the effects that were statistically significant (at least $p<.05$ ) will be discussed. For the orientation $\times$ 
color conjunction searches, the RTs were faster for the fast-fixed-than for the fixed- and the free-viewing conditions. The RT range was greater for the free- than for both fixed-viewing conditions, whereas the opposite was true for errors. Because observers knew that the display would be present for a limited time in the fast-fixedviewing condition, and were asked to respond as fast and as accurately as possible, they may have responded faster. As a consequence, the most errors occurred in the fast-fixed-, and the least errors in the free-, viewing condition, with all conditions differing significantly. The finding that search performance was hampered with shortened display durations could be explained by the fact that the fixed-viewing conditions (1) prevented eye movements, (2) limited the number of covert attentional shifts that could take place while the display was present, and/or (3) reduced the information that could be extracted from the displays. We suggest that these three factors should be considered when theorizing about visual search, instead of covert attention being exclusively focused on as the underlying cause for conjunction searches. As stated by Chmiel (1989), there are problems with inferring properties about central mechanisms when more peripheral mechanisms could also play a role.

The effects of target, set size, and orientation were significant in all three experiments. The effect of target presence was more pronounced for the free-viewing condition than for either of the fixed-viewing conditions in terms of speed, but was more pronounced for the fastfixed-viewing condition in terms of accuracy. Although the set-size effect was present in all conditions, in terms of errors, it was more pronounced in the fast-fixedviewing condition than in the fixed-viewing condition, in which, in turn, it was more pronounced than it was in the free-viewing condition. Our error functions for these fixed-viewing conditions are similar to the sharply increasing error $\times$ set-size functions found by Humphreys and Müller (1993) when response deadlines were imposed. According to these authors, under these conditions, errors are expected to increase with set size at least to some degree, regardless of whether observers are following a parallel (first glance) or serial (with either biased or unbiased guessing) search strategy. More specifically, in testing set sizes of 4-10, these authors assert that the positively accelerating miss rates that are generated by both search via recursive rejection (SERR) and human subjects are in direct contrast to the negatively accelerating functions that would be predicted by a serial search. Our own miss-rate functions also positively accelerated for this set-size range, supporting the notion of a parallel first glance of the display. With larger set sizes, however, miss rates begin to negatively accelerate, and this, according to these authors, is more in line with the predictions of a serial search. The limited range of set sizes implemented by SERR makes it difficult to conclude whether observers are adopting a different strategy for the smaller than for the larger set sizes, or whether there are other factors that are influencing the change in the error-rate patterns.
Although accuracy decreased when display duration was shortened, we feel confident that even in the fastfixed-viewing condition, the observers were able to process a wide range of set sizes. The errors did not increase to the extent that Treisman and Gormican (1988) and Klein and Farrell (1989) had anticipated. Treisman and Gormican used $33 \%$ as a cutoff for error rate of feature-search performance. The comparisons with feature searches under free-, fixed-, and fast-fixed-viewing conditions (Carrasco \& Katz, 1992) indicated that search for conjunctions was more difficult than that for features, as characterized by higher RTs and error rates and more pronounced target-presence and set-size effects. This was expected to be due to the greater complexity of conjunction searches, especially for the larger set sizes used here. Indeed, errors above this cutoff point only occurred for present targets, at large set sizes (24-36), in the fixed-viewing conditions. Further, the errors were not random; the analysis by target position illustrated that high error rates only occurred at the three farthest eccentricities, which is, in itself, a revealing finding.

\section{Conjunction-Orientation Asymmetry}

We found an orientation asymmetry for conjunction searches for the three viewing conditions: The tilted target was detected faster and more accurately than the vertical target for the whole range of set sizes, and the difference was more pronounced for the larger set sizes. On the one hand, given that it is not physiologically possible to have serial processes with such fast search rates (Crick, 1984), a search completed in under $10 \mathrm{msec}$ has been considered to be parallel (e.g., Duncan \& Humphreys, 1989; Enns \& Rensink, 1990a, 1990b; Treisman $\&$ Gormican, 1988); thus, the search for the tilted conjunction target would be considered parallel, whereas that for the vertical would be considered serial (Table 3 ). On the other hand, a search with comparable nonzero target-absent and target-present slopes $(\approx 1: 1)$ has also been used to indicate a parallel process (e.g., Pashler, 1987a; Treisman, 1991; Treisman \& Gelade, 1980; Treisman \& Gormican, 1988; Wolfe et al., 1989), in which case, these same tilted and vertical searches would not be parallel - but would they necessarily be serial? Would they reflect an asymmetry? Such a discrepancy between different indices used to classify search as being parallel or serial underscores the fact that although analyses of slope and slope ratios are informative, they may not always provide an accurate representation of the search function (Cheal \& Lyon, 1992; Humphreys \& Müller, 1993; Townsend, 1972, 1990).

The presence of a conjunction-orientation asymmetry extends previous findings of an orientation asymmetry for feature searches under free-viewing conditions (Carrasco \& Katz, 1992; Cavanagh et al., 1990; Treisman 1985, 1986; Treisman et al., 1990; Treisman \& Gormican, 1988). The present results also support Treisman's hypothesis on asymmetries: The features that pop out are those that have a deviating value (e.g., tilt) that generates additional activity when it is compared with the standard 
or reference value (e.g., verticality). On the basis of the premise that the identification of the visual-system primitives is aided by the study of the direction of the search asymmetry (Cavanagh et al., 1990; Treisman, 1985, 1986; Treisman et al., 1990; Treisman \& Gormican, 1988), the conjunction asymmetry found here supports the notion that orientation is a primitive feature. Further, this conjunction-orientation asymmetry also lends support to the proposition that conjunction-search processes operate at the level of features, and that search-rate trends can be predicted for conjunctions by assuming additive contributions from the component features (Treisman \& Sato, 1990). Moreover, on the basis of GS tenets (Wolfe, 1992, 1994; Wolfe \& Cave, 1990; Wolfe et al., 1989), these findings may indicate that the tilted line, which may have a greater salience and left-right activation, facilitated the search for the tilted conjunction target more than the less salient vertical target that contributes no left-right activation. If no guidance from the features to the conjunctions were available, conjunction asymmetries would not emerge. The mere existence of a conjunction asymmetry contradicts any views of conjunction search based on blind serial search.

According to Cohen (1993), who has recently found conjunction asymmetries with no detectable asymmetries between the individual features that make up conjunctive targets, search rate of individual features cannot predict search rate for conjunctive targets. To predict the slope for conjunction searches, it is necessary to know the particular dominance relations between the features in each of the conjunctive target's dimensions, as well as the relative discriminability of features within a dimension. Along with Treisman and Gormican (1988), he proposed that feature asymmetries result from searches in which the target and distractors are too similar to be registered in separate maps, and the visual system has to pool their activation together; he concluded that when targets and distractors are sufficiently distinct, their similarity does not play a role in feature searches.

In contrast to Cohen (1993), we have obtained an orientation asymmetry for both feature searches (Carrasco \& Katz, 1992) and conjunction searches. Further, the orientation asymmetry was more pronounced for features than for conjunctions. This could be attributed to the more basic nature of the feature search and to the fact that the conjunction stimuli are made up of combinations of features. The target orientation was not the only relevant dimension for the conjunction search; the other dimension, color, also contributed to the search pattern. Because the blue and red we used are prototype colors (e.g., Treisman \& Gormican, 1988; Wolfe, 1994), they were not expected to be processed in an asymmetrical fashion. As a result, the introduction of the color dimension may have reduced the signal-to-noise ratio, and thus diluted or diminished the extent of the orientation asymmetry. Had we used orientation in conjunction with another dimension for which there is an asymmetry (e.g., size), the effects may have been additive, and a stronger conjunction asymmetry could have emerged.
The conjunction asymmetries obtained in this study are not directly comparable to Cohen's (1993) asymmetries because we investigated a color $X$ orientation conjunction, whereas he explored orientation $\times$ size, orientation $X$ contrast, and color $X$ shape conjunctions. Moreover, our feature searches had homogeneous distractors (Carrasco \& Katz, 1992), but in three out of four of Cohen's experiments, the distractors were heterogeneous (e.g., in Experiment 2, the target was a small horizontal line and the distractors were large horizontal and large vertical lines). Had he used homogeneous distractors, feature asymmetries might well have emerged. In addition, it is presumed that an asymmetry is more likely to occur when the orientations of target and distractors differ minimally-about $15^{\circ}-18^{\circ}$ (Cohen, 1993; Treisman \& Gormican, 1988). This is due to the standard feature's activation of only a prototypical channel, and the deviating feature's activation of not only a prototypical channel, but also their own. Carrasco and Katz, however, found asymmetries for targets deviating from the vertical target by $45^{\circ}$; searching for the tilted target among vertical distractors was faster and more accurate than searching for the vertical target among tilted distractors. Likewise, in the present study, the tilted targets deviated from the vertical by $45^{\circ}$.

\section{CONCLUSION}

This article agrees with Eriksen's (1990) point that although attention can expedite the processing of visual stimuli, the spatial resolution of the retina limits what attention can accomplish, suggesting that spatial resolution is the major determinant of the eccentricity effect found here. Moreover, the similarity of the eccentricity effect between conjunction and feature searches strengthens our claim that spatial resolution plays a significant role in this effect. Likewise, for a letter-recognition task, Eriksen and Schultz (1977) concluded that increases in RTs at peripheral eccentricities were due to peripheral stimulus degradation factors (such as acuity) rather than to more central cognitive processes. Our findings, together with other research that has shown that visual attention is sensitive to visual angle, retinal and cortical resolution, and depth (Downing \& Pinker, 1985), point to the need for models of visual search to take into account the physiological constraints of the visual system.

Our detailed analysis of slopes did not lend support to the serial self-terminating hypothesis. Further evidence against a strict serial search came from our finding of conjunction-orientation asymmetry under free- and fixedviewing conditions: The tilted target was detected faster and more accurately among tilted and vertical distractors than the vertical target was detected among vertical and tilted distractors. This orientation asymmetry had also been reported in a feature search (Carrasco \& Katz, 1992). Note that finding asymmetries with $45^{\circ}$ contradicts Treisman's $(1991,1993)$ statement that left and right diagonals are standard values for the orientation dimension. Further, her proposal seems counterintuitive, given the 
oblique effect - that is, the general superiority in the visibility of horizontal and vertical lines (Appelle, 1972), which seems to be related to the fact that more neurons are tuned to detect vertical or horizontal lines than to detect oblique lines (Mansfield, 1974), and that thresholds for vertical gratings are lower than those for diagonal gratings (Campbell, Kulikowski, \& Levinson, 1966).

More important, we have also shown that target location critically affects conjunction-search performance. The eccentricity effect shows that search efficiency, as assessed by both latency and accuracy, gradually decreases as the target is located farther away from the fixation point. Indeed, when performance is assessed by collapsing across different eccentricities, conclusions drawn from the data may be confounded; rather than reflecting the nature of the search (i.e., parallel vs. serial), the data may reflect peripheral versus central target locations. Further, given the higher probability of the target's appearing at periphery as set size increases, and also given the interaction of the eccentricity effect with set size, we suggest that the set-size effect, commonly relied upon to indicate covert attentional shifts, is confounded by eccentricity.

On the basis of the prevalent and consistent eccentricity effect found under the three viewing conditions, and the fact that the eccentricity effect was not more pronounced when more covert attentional shifts may have been involved, we suggest that spatial resolution and lateral inhibition may account for the eccentricity effect. Moreover. we propose that these, as well as other factors, such as range of set sizes used, display size, and display density, have to be taken into consideration before meaningful comparisons among different search studies can be made.

\section{REFERENCES}

Anderst.n. G. J. (1990). Focused attention in three-dimensional space Perezpion \& Psychophisics, 47. 112-120.

Andersen, G. J., \& Kramer, A. F. (1993). Limits of focused attention in three-dimensional space. Perception \& Pstchophisics. 53, 658667

APpel.1.E, S. (1972). Perception and discrimination as a function of stimulus orientation: The oblique effect in man and animals. Psychological Bulletin, 78, 266-278.

Bacon, W., \& EGETH, H. (1991). Local processes in preattentive feature detection. Jou'nal of Experimental Psychologi: Human Perception \& Performance, 17, 77-90.

Banks, W. P., \& Prinzmetal, W. (1976). Configurational effects in visual information processing. Perception \& Psychophysics, 19, 361367

Bergen, J. R. \& Jules7, B. (1983, June 23). Parallel versus serial processing in rapid pattern discrimination. Nature, 303,696-698.

Bifderman, 1., \& COOPER, E. E. (1991), Object recognition and laterality null cffects. Neuropsychologia. 29, 685-694.

BReItmeyer, B. G. (1984). Visual masking: An integrative approach. New York: Oxford University Press.

Bundesten, C.. \& Pedersen, L. F. (1983). Color segregation and visual search. Perception \& Psychophysics, 33, 487-493.

Campbei.l., F. W., Kui.jkowski, J. J., \& Levinson, J. (1966). The effect of orientation on the visual resolution of gratings. Joumal of Physiolog! , 187, 427-436.

Cannon, M. W., JR. (1985). Perceived contrast in the fovea and periphery. Journal of the Optical Society of America, 2, 1760-1768.
Carrasco, M., \& Katz., S. M. (1992). Exploring feature asymmetries in visual search: Effects of target position and presentation time. Proceedings \& Abstracts of the Annual Meeting of the Eastern Psychological Association, 63, 25.

Carrascu, M., Katz, S. M., \& Chang, I. (1993). Spatial resolution versus covert attention: Position effects on visual search tasks [Abstract]. Perception. 22 (Suppl.), 69.

Cavanagh, P., Arguin, M., \& Treisman, A. (1990). Effect of surface medium on visual search for orientation and size features. Journal of Experimental Psychology: Human Perception \& Performance, 16, 479-491.

Cheal, M. L., \& Lron, D. R. (1989). Attention effects on form discrimination at different eccentricities. Quarterly Journal of Experimental Psychologr, 41 A. 719-746.

CheAL, M., \& Lyon, D. R. ( (992). Attention in visual search: Multiple search classes. Perceptien \& Psychophysics, 52, 113-138.

Chmifl, N. (1989). Response effects in the perception of conjunctions of colour and form Psychological Research, 51, 117-122.

CoH:N. A. (1993). Asymmetries in visual search for conjunctive targets. Journal of Experimental Psychology: Human Perception \& Performance, 19. 775-797.

CrICk. F. (1984). Function of the thalamic reticular complex: The searchlight hypothesis. Proceedings of the National Academy of Sciences, 81, 4586-4590.

DeValots, R. L., \& DeValois, K. K. (1988). Spatial vision. New York: Oxford University Press.

Donnflly, N., Humphreys, G. W., \& Ridnoch, M. J. (1991). Parallel computation of primitive shape descriptions. Journal of Experimental Psychology: Human Perception \& Performance. 17. 561-570.

Downing, C. J. (1988). Expectancy and visual-spatial attention: Effects on perceptual quality. Journal of Experimenual Psychology: Human Perception \& Performance, 14, 188-20)2.

Downing, C. J., \& Pinker, S. (1985). The spatial structure of visual attention. In M. I. Posner \& O. S. M. Martin (F.ds.), Attention and performance $X /$ (pp. 171-187). Hillsdale, NJ: Erlbaum.

Duncan, J., \& Humphreys, G. W. (1989). Visual search and stimulus similarity. Psychological Review, 96, 433-458.

Duncan, J., \& Humphreys, G. W. (1992). Beyond the search surface: Visual search and attentional engagement. Journal of Experimental Psichology: Human Perception \& Performance, 18, 578-588.

Efron, R., Yund, E. W., \& Nichols, D. R. (1987). Scanning the visual field without eye movements-a sex difference. Neuropsychologia, 25, 637-644.

Erron, R., Yund, E. W., \& Nichols, D. R. ( 1990a). Detectability as a function of target location: Effects of spatial configuration. Brain \& Cognition, 12,102-116.

EFron, R., YUnd, E. W., \& Nichols, D. R. ( 1990b). Serial processing of visual spatial patterns in a search paradigm. Brain \& Cognition, $12,17-41$.

EFron, R., YUND, E. W., \& Nichols, D. R. (1990c). Visual detectability gradients: The effect of distractors in contralateral field. Brain \& Cognition, 12, 128-143.

Egeth, H.. \& Dagenbach, D. (1991). Parallel vs. serial processing in visual search: Further evidence from subadditive effects of visual quality. Journal of Experimental Psychology: Human Perception \& Performance, 17, 551-560.

Egeth, H. J., Fol K, C. L., \& Mullen, P. A. (1989). Spatial parallelism in the processing of lines, letters, and lexicality. In B. E. Shepp \& S. Ballesteros (Eds.), Object perception: Structure and process (pp. 19-52). Hillsdale, NJ: Erlbaum.

Egierh, H. J., Virzi, R. A., \& Garbart, H. (1984). Searching for conjunctively defined targets. Journal of Experimental Psychology: Human Perception \& Performance, 10, 32-39.

EnNs, J. T., \& Rensink, R. A. (1990a, February 9). Influence of scenebased properties on visual search. Science, 247, 721-723.

Enns, J. T.. \& Rensink, R. A. (1990b). Sensitivity to three-dimensional orientation in visual search. Psvchological Science, 1, 323-326.

ERIKSEN, C. W. (1990). Attentional search of the visual field. In D. Brogan (Ed.), Visual search (pp. 3-19). London: Taylor \& Francis.

Eriksen, C. W., \& Murphy, T. D. (1987). Movement of attentional focus across the visual field: A critical look at the evidence. Perception \& Psychophysics, 42, 299-305. 
ERIKSEN, C. W., \& ST. JAMES, J. D. (1986). Visual attention within and around the field of focal attention: A zoom lens model. Perception \& Psychophysics, 40, 225-240.

Eriksen, C. W., \& Schultz, D. W. (1977). Retinal locus and acuity in visual information processing. Bulletin of the Psychonomic Society, 9, 81-84

Eriksen, C. W., \& Webb, J. M. (1989). Shifting of attentional focus within and about a visual display. Perception \& Psychophysics, 45, 175-183.

ERIKSEN, C. W., \& YeH, Y. (1985). Allocation of attention in the visual field. Journal of Experimental Psychology: Human Perception \& Performance, 11, 583-597.

Estes, W. K., \& WoLforD, G. L. (1971). Effects of spaces on report from tachistoscopically presented letter strings. Psychonomic Science, 25, 77-80.

FARMER, E. W., \& TAYLOR, R. M. (1980). Visual search through color displays: Effects of target-background similarity and background uniformity. Perception \& Psychophysics, 27, 267-272.

Fischer, B., \& RAMSPERGER, E. (1984). Human express saccades: Extremely short reaction times of goal directed eye movements. Experimental Brain Research, 57, 191-195.

FISCHER, B., \& WEBER, E. (1993). Express saccades and visual attention. Behavioral \& Brain Sciences, 16, 553-610.

Graham, N. (1981). Psychophysics of spatial-frequency channels. In M. Kubovy \& J. R. Pomerantz (Eds.), Perceptual organization (pp. 1-25). Hillsdale, NJ: Erlbaum.

Heron, W. (1957). Perception as a function of retinal locus and attention. American Journal of Psychology, 70, 38-48.

HuMPhREYS, G. W., \& MÜlleR, H. J. (1993). Search via recursive rejection (SERR): A connectionist model of visual search. Cognitive Psychology, 25, 43-110.

Humphreys, G. W., Quinlan, P. T., \& RidDOCH, M. J. (1989). Grouping processes in visual search: Effects with single- and combinedfeature targets. Journal of Experimental Psychology: General, 118, 258-279.

Hurlbert, A., \& Poggio, T. (1985). Spotlight on attention. Trends in Neuroscience, 8, 309-311.

JONIDES, J., \& YANTIS, S. (1988). Uniqueness of abrupt visual onset in capturing attention. Perception \& Psychophysics, 43, 346-354.

Julesz, B., \& Bergen, J. R. (1983). Textons, the fundamental elements in preattentive vision and perception of textures. Bell System Technical Journal, 62, 1619-1645.

KinCHLA, R. A. (1992). Attention. Annual Review of Psychology, 43, $711-742$.

KLEIN, R., \& FARRELL, M. (1989). Search performance without eye movements. Perception \& Psychophysics, 46, 476-482.

KRAMER, A. F., \& JACOBSON, A. (1991). Perceptual organization and focused attention: The role of objects and proximity in visual processing. Perception \& Psychophysics, 50, 267-284.

KUMAR, S. (1994). Visual search for two dimensional and three dimensional stimuli. Unpublished master's thesis. Wesleyan University, Middletown, CT.

LABERGE, D. (1983). Spatial extent of attention to letters in words. Journal of Experimental Psychology: Human Perception \& Performance, 9, 371-379.

LefTON, L. A., \& HABER, R. N. (1974). Information extraction from different retinal locations. Journal of Experimental Psychology, 102, 975-980.

Livingstone, M., \& Hubel, D. (1988, May 6). Segregation of form, color, movement, and depth: Anatomy, physiology, and perception. Science, 240, 740-749.

MANSFIELD, R. (1974, December 20). Neural basis of orientation perception in primate vision. Science, 186, 1133-1135.

Mayfrank, L., Kimmig, H., \& Fischer, B. (1987). The role of attention in the preparation of visually guided saccadic eye movements in man. In J. K. O'Regan \& A. Levy-Schoen (Eds.), Eye movements: From physiology to cognition (pp. 37-45). New York: Elsevier, North-Holland.

MCLeod, P., Driver, J., \& CRISP, J. (1988). Visual search for a conjunction of movement and form is parallel. Nature, 332, 154-155.

MishKIN, M., \& ForGAYS, D. G. (1952). Word recognition as a function of retinal locus. Journal of Experimental Psychology, 43, 43-48.
Moraglia, G. (1989a). Display organization and the detection of horizontal line segments. Perception \& Psychophysics, 45, 265-272.

Moraglia, G. (1989b). Visual search: Spatial frequency and orientation. Perceptual \& Motor Skills, 69, 675-689.

MurPhy, T. D., \& ERIKSEN, C. W. (1987). Temporal changes in the distribution of attention in the visual field in response to precues. Perception \& Psychophysics, 42, 576-586.

Nakayama, K., \& Silverman, G. H. (1986). Serial and parallel processing of visual feature conjunctions. Nature, 320, 264-265.

Ostrovsky-Solis, F., Efron, R., \& Yund, E. W. (1991). Visual detectability gradients: Effect of illiteracy. Brain \& Cognition, 17, 42-51.

PAshler, H. (1987a). Detecting conjunctions of color and form: Reassessing the serial search hypothesis. Perception \& Psychophysics, 41, 191-201.

PASHLER, H. (1987b). Target-distractor discriminability in visual search. Perception \& Psychophysics, 41, 285-292.

Pashler, H., \& Badgio, P. C. (1985). Visual attention and stimulus identification. Journal of Experimental Psychology: Human Perception \& Performance, 11, 105-121.

Poisson, M. E., \& Wilkinson, F. (1992). Distractor ratio and grouping processes in visual conjunction search. Perception, 21, 21-38.

Posner, M. I., SNyder, C. R. R., \& Davidson, B. J. (1980). Attention and the detection of signals. Journal of Experimental Psychology: General, 109, 160-174.

Previc, F. H. (1990). Functional specialization in the lower and upper visual fields in humans: Its ecological origins and neurophysiological implications. Behavioral \& Brain Sciences, 13, 519-575.

Prinzmetal, W., Presti, D. E., \& Posner, M. I. (1986). Does attention affect visual feature integration? Journal of Experimental Psychology: Human Perception \& Performance, 12, 361-369.

Quinlan, P. T., \& Humphreys, G. W. (1987). Visual search for targets defined by combinations of color, shape, and size: An examination of the task constraints on feature and conjunction searches. Perception \& Psychophysics, 41, 455-472.

RiJsdiJk, J. P., Kroon, J. N., \& van der Wilt, G. J. (1980). Contrast sensitivity as a function of position on the retina. Vision Research, 20, 235-241.

SaARINEN, J., \& Julesz, B. (1991). The speed of attentional shifts in the visual field. Proceedings of the National Academy of Science, 88, 1812-1814.

SAGI, D., \& JulESZ, B. (1987). Short-range limitation on detection of feature differences. Spatial Vision, 2, 39-49.

SAVEL, T. G. (1991). Effects of isoluminance and other variables on visual search tasks. Unpublished honors thesis, Wesleyan University, Middletown, CT.

Shulman, G. L., Sheehy, J. B., \& Wilson, J. (1986). Gradients of spatial attention. Acta Psychologica, 61, 167-181.

Shulman, G. L., \& Wilson, J. (1987). Spatial frequency and selective attention to local and global information. Perception, 16, 89-101.

Steinman, S. B. (1987). Serial and parallel search in pattern vision? Perception, 16, 389-398.

TOWNSEND, J. T. (1972). Some results concerning the identifiability of parallel and serial processes. British Journal of Mathematical and Statistical Psychology, 25, 168-199.

TOWNSEND, J. T. (1990). Serial vs. parallel processing: Sometimes they look like Tweedledum and Tweedledee but they can (and should) be distinguished. Psychological Science, 1, 46-54.

Treisman, A. (1982). Perceptual grouping and attention in visual search for features and for objects. Journal of Experimental Psychology: Human Perception \& Performance, 8, 194-214.

Treisman, A. (1985). Preattentive processes in vision. In $Z$. W. Pylyshyn (Ed.), Computational processes in human vision: An interdisciplinary perspective (pp. 341-369). Norwood, NJ: Ablex.

Treisman, A. (1986). Features and objects in visual processing. In 1. Rock (Ed.), The perceptual world (pp. 97-110). New York: Freeman.

Treisman, A. (1988). Features and objects: The Fourteenth Bartlett Memorial Lecture. Quarterly Journal of Experimental Psychology, 40A, 201-237.

Treisman, A. (1990). Variations on the theme of feature integration: Reply to Navon (1990). Psychological Review, 97, 460-463.

TREISMAN, A. (1991). Search, similarity, and integration of features be- 
tween and within dimensions. Journal of Experimental Psychology: Human Perception \& Performance, 17, 652-676.

Treisman, A. (1993). The perception of features and objects. In A. Baddeley \& L. Weiskrantz (Eds.), Attention: Selection, awareness, and conirol (pp. 5-35). Oxford: Oxford University Press, Clarendon Press.

Treisman, A., Cavanagh, P., Fischer, B., Ramachandran, V. S., \& VON DER HEYDT, R. (1990). Form perception and attention: Striate cortex and beyond. In L. Spillman \& J. S. Werner (Eds.), Visual perception neurophysiological foundations ( $\mathrm{pp}$. 273-316). San Diego, CA: Academic Press.

Treisman, A., \& Gelade, G. (1980). A feature integration theory of attention. Cognitive Psychology, 12, 97-136.

Treisman, A., \& Gormican, S. (1988). Feature analysis in early vision: Evidence from search asymmetries. Psychological Review, 95, 15-48.

Treisman, A., \& Sato, S. (1990). Conjunction search revisited. Journal of Experimental Psychology: Human Perception \& Performance, 16, 459-478.

Treisman, A., \& Souther, J. (1985). Search asymmetry: A diagnostic for preattentive processing of separable features. Journal of Experimental Psychology: General, 114, 285-310.

WARD, R., \& MCClElland, J. L. (1989). Conjunctive search for one and two identical targets. Journal of Experimental Psychology: Human Perception \& Performance, 15, 664-672.

WOLFE, J. M. (1992). The parallel guidance of visual attention. Current Directions in Psvchological Science, 1, 124-128.

WolfE, J. M. (1994). Guided Search 2.0: A revised model of visual search. Psychonomic Bulletin \& Review, 1, 202-238.

WOLFE, J. M., \& CAVE, K. R. (1990). Deploying visual attention: The guided search model. In A. Blake \& T. Troschianko (Eds.), Al and the eve (pp. 80-103). Chichester, MA: Wiley.

Wolfe, J. M., Cave, K. R., \& Franzel, S. L. (1989). Guided Search: An alternative to the feature integration model for visual search. Journal of Experimental Psychology: Human Perception \& Performance, 15, 419-433.

Wolfe, J. M., YU, K. P., Stewart, M. I., Shorter, A. D., \& Cave, K. R. (1990). Limitations on the parallel guidance of visual search: Color $x$ color and orientation $X$ orientation conjunctions. Journal of Experimental Psychology: Human Perception \& Performance, 16, 879892

WOLFORD, G. (1975). Perturbation model for letter identification. Psychological Review, 82, 184-199.

WOLFORD, G., \& SHUM, K. H. (1980). Evidence for feature perturbatinns. Perception \& Psychophysics, 27, 409-420.

Yund, E. W., EFron, R., \& Nichols, D. R. (1990a). Detectability as a function of spatial location: Effects of selective attention. Brain \& Cognition, 12, 42-54.

Yund, E. W., EFron, R., \& Nichols, D. R. (1990b). Detectability gradients as a function of target location. Brain \& Cognition, 12, 1-16.

Yund, E. W., Efron, R., \& Nichols, D. R. (1990c). Target detection in one visual field in the presence or absence of stimuli in the contralateral field by right- and left-handed subjects. Brain \& Cognition, 12, 117-127.

ZeLINSKY, G. J. (1994). Eye movements during parallel/serial search tasks. Unpublished doctoral dissertation, Brown University, Providence, RI.

Zelinsky, G. J., Sheinberg, D. L., \& Bulthoff, H. H. (1993). Eye movements during visual search. Investigative Ophthalmology \& Visual Science, 34, 1236.

\section{NOTES}

1. When we submitted this paper for publication, conjunction asymmetries had not been reported. Cohen (1993) has recently published an article that deals with conjunction asymmetries. We will compare our findings with his in the General Discussion.

2. The way in which negative slope values for absent and/or present trials are treated could have different effects on the statistical analysis and interpretation of the data. In Pashler's (1987a) study, for those observers who had negative slopes for present trials and positive slopes for absent trials, an arbitrary maximal value was assigned to the absent/ present slope ratio because this ratio was not defined. This approach is not necessarily the best, since the maximal value assigned to the ratio is a biased estimate. On the other hand, he did not report how he analyzed the absent/present ratios of those observers whose slopes for the absent trials were negative, while their slopes on the present trials were positive. Further, because of the negative slopes, he did not conduct a $t$ test on the mean absent/present ratio to test the 2:1 hypothesis as he did for the data in which no negative values were present. The other studies in which individual slope data also revealed negative slopes did not deal with them in detail (Treisman, 1982, 1991; Wolfe et al., 1989, Experiment 9).

In the present analysis, the negative slopes were included in the twotailed $t$ tests, not just the mean ratio averaged across all observers. For the binomial tests, when the absent slope was negative and the present slope positive, and also when both were negative, the slope ratios were considered to be theoretically closer to a 1:1 ratio and were thus counted below the 1.5 cutoff. Egeth, Folk, and Mullen (1989) advised that while a positive slope can indicate either a parallel or serial process, a negative slope can only be indicative of a parallel process.

3. The VSearch (University of British Columbia) program was used. The impossibility of including all 9 set sizes in the same block does not affect the results. Pashler and Badgio (1985) showed that their slope results do not depend upon whether smaller set sizes are used exclusively or whether they are used in conjunction with larger set sizes. Further, results from our lab (Kumar, 1994) indicate that there is no effect when comparing performance when set sizes are blocked together (e.g., small (1-12) vs. large (12-24) or intermixed over a range of $1-24)$.

4. Correlations of RTs per position for Experiments 1 and 2, 1 and 3 , and 2 and $3: r(35)=.49, p<.01 ; r(35)=.60, p<.001 ;$ and $r(35)=$ $.64, p<.001$, respectively. Correlations of errors per position for Experiments 1 and 2,1 and 3 , and 2 and $3: r(35)=.31, p<.10 ; r(35)=$ $.58, p<.001$; and $r(35)=.81, p<.001$, respectively. Correlations of RTs and errors per position for the three experiments: Experiment 1: $r(35)=.28, p<.01$; Experiment $2: r(35)=.49, p<.01$; Experiment 3 : $r(35)=.69, p<.001$.

5. RT: $p<.01$; errors: $p<.10$. The error correlations were not as high as the RT correlations because the eccentricity effect was less pronounced for errors than for RT, especially for features.

6. We included a comparison between upper and lower visual fields due to Previc's (1990) suggestions that they are functionally specialized for far and near vision, respectively, and that the latency of RTs to most stimuli is shorter in the lower visual field than in the upper visual field.

7. This possibility was suggested by one of the reviewers (Jeremy Wolfe).

8. Although Savel's (1991) data had not been originally analyzed as a function of target eccentricity, because we had RT and error data for each target location we could perform the eccentricity analysis of this study.
(Manuscript received August 9, 1993; revision accepted for publication April 16, 1995.) 